\title{
Cell-Specific Aptamers as Emerging Therapeutics
}

\author{
Cindy Meyer, Ulrich Hahn, and Andrea Rentmeister \\ Chemistry Department, MIN Faculty, Institute for Biochemistry and Molecular Biology, Hamburg University, \\ Martin-Luther-King-Platz 6, 20146 Hamburg, Germany
}

Correspondence should be addressed to Andrea Rentmeister, rentmeister@chemie.uni-hamburg.de

Received 16 May 2011; Accepted 23 June 2011

Academic Editor: Souvik Maiti

Copyright (c) 2011 Cindy Meyer et al. This is an open access article distributed under the Creative Commons Attribution License, which permits unrestricted use, distribution, and reproduction in any medium, provided the original work is properly cited.

\begin{abstract}
Aptamers are short nucleic acids that bind to defined targets with high affinity and specificity. The first aptamers have been selected about two decades ago by an in vitro process named SELEX (systematic evolution of ligands by exponential enrichment). Since then, numerous aptamers with specificities for a variety of targets from small molecules to proteins or even whole cells have been selected. Their applications range from biosensing and diagnostics to therapy and target-oriented drug delivery. More recently, selections using complex targets such as live cells have become feasible. This paper summarizes progress in cell-SELEX techniques and highlights recent developments, particularly in the field of medically relevant aptamers with a focus on therapeutic and drugdelivery applications.
\end{abstract}

\section{Introduction}

Aptamers are short nucleic acids (typically 12-80 nucleotides long) capable of specific and tight binding to their target molecules. The term aptamer is derived from the Latin word aptus (fitting) and the Greek word meros (part). Aptamers are selected by a process called SELEX (systematic evolution of ligands by exponential enrichment), which was established independently by Ellington and Szostak [1], Tuerk and Gold [2], and Robertson and Joyce [3] in 1990. A typical SELEX experiment starts with a library of up to $10^{15}$ random oligonucleotides, which can be DNA, RNA, or modified RNA (e.g., $2^{\prime}$-OMe or $2^{\prime}$-F). Some members of this enormous library are anticipated to bind a desired target. The key step of the SELEX procedure is to efficiently separate those few from the nonbinding species. Selected nucleic acids are then amplified and used for further selection rounds. A successful SELEX experiment will usually result in a collection of aptamers, which can subsequently be cloned and tested individually for their binding properties.

The possible aptamer targets show a great diversity ranging from small molecules, like organic dyes [4], amino acids [5] or antibiotics [6], peptides [7], proteins [8], and viruses [9] to whole cells [10]. The dissociation constants ( $K_{d}$ values) of aptamer-target complexes are comparable to those of antibodies and can reach the picomolar range. In addition, aptamers exhibit the following interesting features, which set them apart from antibodies: they are selected entirely in vitro, their synthesis has been automated, and they can easily be chemically modified [11]. Furthermore, they can be stored and shipped without problems, because the stability of DNA aptamers, in particular, is almost infinite. Importantly, they are not immunogenic. Due to their binding properties, aptamers have become useful tools for diagnostic and therapeutic applications $[12,13]$.

The first representative of an aptamer drug is Macugen, a highly modified RNA aptamer for treatment of age-related macular degeneration (AMD), which has been released in 2004 [14].

In this paper, we are focusing on recent developments in the selection of aptamers for complex targets and their application in diagnostics and therapy. We are emphasizing the potential of cell-based aptamer selections (cell-SELEX) as a means to enrich binders to live cells and highlight the potential of recent technical advances.

\section{Aptamers for Intra- and Extracellular Targets and Their Application}

Alternatively: for each class of targets, aptamers show outstanding characteristics. For small molecules, aptamers were 
found that discriminate between closely related targets, such as caffeine and theophylline [15], differing by a single methyl group, or adenosine triphosphate and adenosine monophosphate (differing by their $5^{\prime}$-phosphorylation state) [16] These aptamers have been successfully used as diagnostic tools and have been recently reviewed [17].

Nucleic acid-binding proteins, like Tat [18] and Rev [19] of HIV-1, were found to be excellent protein targets yielding high-affinity aptamers. However, numerous examples proved that nucleic acid binding is not a required target property for the selection of tightly and specifically binding aptamers. Several examples will be mentioned in this paper. There are many ways of classifying aptamer targets into different groups. Here, we want to distinguish between intracellular and extracellular targets.

Intracellular targets are difficult to address in living cells, because cytosolic delivery of aptamers, so-called intramers, in sufficient quantities is not facile. The problem becomes even harder for the delivery of aptamers in vivo. Most of the applied methods rely on protocols established for siRNA-transfection which have been recently summarized in excellent reviews $[20,21]$. Briefly, lipofection-based methods are technically simple but do not always yield sufficient amounts of cytosolic aptamer to cause measurable effects. There are few examples for the successful delivery of aptamers into cells. An aptamer specific for the N-terminal part of cytohesin-2 was successfully transferred into cells via lipofection and led to downregulation of the serummediated MAPK activation [22]. Another example that should be mentioned here is an EGFRvIII-binding aptamer that intracellularly binds to the unglycosylated form of the receptor, thereby disrupting its posttranslational modifications [23].

The main alternative to lipofection is the intracellular production of the intramers by generating appropriate aptamer overproducing cell lines. This process has been realized by the application of different expression vectors $[24,25]$ and by adeno- [26] or vaccinia-virus-based expression systems [27]. However, the generation of stably transfected cell lines is time consuming and of limited use for therapeutic applications. These difficulties may explain why there is a big gap between the number of aptamers available for intracellular targets and the number of successfully used intramers. Consequently, there is a concern whether intramers are suitable therapeutic agents in vivo. A smart way to circumvent the aptamer delivery problem is to find cell-permeable inhibitory small molecules interfering with the aptamer-protein interaction by aptamer displacement screening [28].

Apart from aptamers for intracellular molecules, a variety of aptamers has been selected that bind extracellular proteins. The latter aptamers have the big advantage that they can be administered intravenously or subcutaneously. We can distinguish between shedded and cell-surface bound targets. Only the latter are within the scope of this paper.

In the case of extracellular targets, aptamer stability becomes a major issue. Therefore, stabilized RNA (e.g., by $2^{\prime}$ $O$-methyl or $2^{\prime}$-fluoro modifications [29-32]) or DNA is preferable when extracellular proteins are targeted. Even then, degradation and clearance is inevitable, and repeated administration will be required until treatment is complete.

\section{Cell-Specific Aptamers}

Aptamers for extracellular targets have high potential for diagnostic and therapeutic applications. For diagnostics, their ability to differentiate among different cell types, namely, between tumor cells and normal cells, is highly interesting. More specialized aptamers can even be applied to distinguish between different types of cancers. In therapy, aptamers for extracellular targets can be used directly as effectors (activators or inhibitors) or indirectly as vehicles for drug delivery.

Surfaces of live cells and parasites represent very complex and convoluted targets. Although it is clear that the cell surface contains many recognition elements, for example, tumor markers in the case of cancer cells, its exact composition is unknown. Subtle differences in cell surface compositions can be very important and may be associated with the differentiation of cells and the onset of malignancies. Analyzing these changes and elucidating the exact composition of different cell types can yield important insights into the molecular details associated with these transformations. However, analysis of the molecular composition (e.g., by protein sequencing and mass spectrometric identification) is not sufficient to identify binders capable of targeting specific cell types.

Cell-SELEX is an evolutionary approach, and thus allows the selection of aptamers even without prior knowledge of specific targets [33-35]. In theory, cell-SELEX may generate aptamers for multiple targets in parallel. Another benefit of the cell-SELEX process is that it generates aptamers for accessible cell-surface markers. Aptamers can, therefore, speed up the discovery of new biomarkers that are per se targetable.

Of course, several cell-surface markers that can be used as target molecules in the traditional SELEX process have already been identified. Using purified proteins as tar-get molecules certainly raises the odds of obtaining ap-tamers for this exact target molecule. However, cell-surface proteins tend to be membrane bound and often cannot be easily purified. In many cases, recombinant production and purification of extracellular domains is possible, but there is a concern whether the domain will still adopt the native conformation. In the worst case scenario, one could select aptamers that will only bind to the purified protein or protein domain and do not recognize the native form on living cells. This risk can be eliminated using cellSELEX. Here, all the cell-surface molecules are presented in their natural surrounding and native conformation and, moreover, contain possible posttranslational modifications.

\section{Recent Advances in Cell-SELEX}

4.1. Different Ways of Obtaining Cell-Specific Aptamers. There has been a long-standing interest in the selection of aptamers for complex targets. Already in 1998, Gold and 
coworkers used human red blood cell membranes as a model system to determine if SELEX could be used for a complex mixture of potential targets [36]. Aptamers for multiple targets were generated simultaneously during the selection process, and the binding affinities of these aptamers for their targets turned out to be comparable to those found in similar experiments with pure targets [36]. Using a secondary selection scheme (deconvolution SELEX), the authors rapidly isolated the aptamers for targets of special interest within the mixture.

In many cases, binding to a specific cell-type can be achieved by selecting aptamers for an abundantly presented protein on the cell-surface using traditional protein SELEX. Subsequently, the selected aptamers have to be tested for their ability to bind the native protein presented on the cell surface. One example is the in vitro selection of RNA aptamers using recombinant L-selectin as target molecule [37]. The resulting aptamers bound L-selectin with about $10^{5}$ times higher affinity than the conventional oligosaccharide ligand sialyl Lewis $X$ [37]. The nuclease stabilized aptamers showed calciumdependent binding to native L-selectin on peripheral blood lymphocytes and blocked L-selectin-dependent interactions with the natural ligands on high endothelial venules. In a different approach, also DNA aptamers were selected with purified L-selectin. These even showed effects on lymphocyte trafficking in vivo [38].

Chen et al. selected RNA aptamers for the extracellular domain of the human epidermal growth factor receptor3 (HER3) produced in insect cells and demonstrated that the aptamers interfere with receptor activation in MCF7 cells [39]. Another example for this strategy is the selection of $2^{\prime}$-F-modified aptamers using murine OX40 human IgG Fc fusion protein, a member of the tumor necrosis factor receptor superfamily [40].

Although the aforementioned examples were successful, it would be preferable to use the native form of the cell surface protein directly. However, cell surfaces are very complex targets. If aptamers for a specific target molecule within the cell surface are desired, cell-SELEX bears the risk to select aptamers for molecules different from the desired target. Therefore, some laboratories have combined selections using purified target proteins with cell-SELEX. Examples include aptamers for E-selectin and tenascin-C: ESelectin is a cell adhesion molecule presented only on endothelial cells activated by cytokines. Mann et al. obtained thioaptamers binding to endothelial cells presenting E-selectin [41]. Tenascin- $C$ is an extracellular matrix protein that is overproduced during tissue remodeling processes, including tumor growth. Hicke et al. performed protein SELEX, cellSELEX, and a crossover of both and selected aptamers with $K_{d}$ values in the low nanomolar range [42].

Although both, the traditional SELEX and a combined approach with cell-SELEX, have been successfully applied for known targets, they do not exploit the full range of possibilities that cell-SELEX has to offer. If live cells are used, there is no need for prior information of the cell surface composition-a true asset. Figure 1 shows a schematic cellSELEX process including the most common separation methods, which are centrifugation of cells in suspension, washing of adherent cells, and fluorescence activated cell sorting (FACS).

As complex target for a cell-SELEX, Homann and Göringer used live Trypanosoma brucei, a sleeping sickness causing protozoan parasite [43]. Nonbinding nucleic acids were removed by repeated cycles of washing and centrifugation. Finally, they identified RNA aptamers specific for a $42-\mathrm{kDa}$ protein located in the parasite's flagellar pocket. Bruno and Kiel selected DNA-aptamers for different spores such as Anthrax or Bacillus thuringiensis [44].

Blank et al. used endothelial cells as targets and selected DNA aptamers that could be used as histological markers of microvessels in brain tumors [45]. Partitioning of bound and unbound ssDNA molecules was done by centrifugation. The progress of the selection as well as the binding properties of individual aptamers were analyzed by FACS.

Gold and coworkers perforemed cell-SELEX using the tumor cell line glioblastoma U251 as target. They selected DNA aptamers for tenascin-C by simply incubating the nucleic acids with cell monolayers in serum-free medium and repeated washing steps [46].

This technique was also used by Tan and coworkers who published multiple aptamers that bound selectively to certain cancer cell lines [47]. To do so, they performed a counter selection with a control cell line before the actual incubation step to remove cell matrix binders. Table 1 gives an overview of cell lines used for live cell-SELEX.

4.2. Technical Challenges and Advances in Cell-SELEX. Until recently, most technical advances of the SELEX procedure focused on improving the individual steps of the process, in particular the actual selection step, in order to make the generation of aptamers as fast and efficient as possible. The main points for optimization are automation, separation, counter selection, and the partitioning of dead cells. Automation of the SELEX process was introduced by Ellington and coworkers [48]. As a consequence, selection times were significantly reduced. Since then, aptamers are also com-mercially available.

Further optimization is required to avoid matrix-binding species within an in vitro selection. In the classical protocol for SELEX, the target protein is immobilized on a solid support such as agarose, sepharose, or magnetic beads. The latter have become particularly popular due to low matrix binding. Alternative separation protocols include filter binding and innovative approaches such as capillary electrophoresis [49]. As mentioned above, the classical approaches have been used successfully to select aptamers for cell-surface proteins that recognize specific live cells.

Target immobilization however, is not compatible with live cells. Most cell-SELEX protocols so far separate binding from nonbinding nucleic acids by washing (adhesive cells) or centrifugation (cells growing in suspension). For obvious reasons it is not easy to enrich exclusively the desired targetbinding species in complex target SELEX approaches, and therefore, counter selections have to be applied in most cases (Table 1).

Cerchia et al. performed even two of those counter selections, one with suspended parental Pc12 cells and a second 


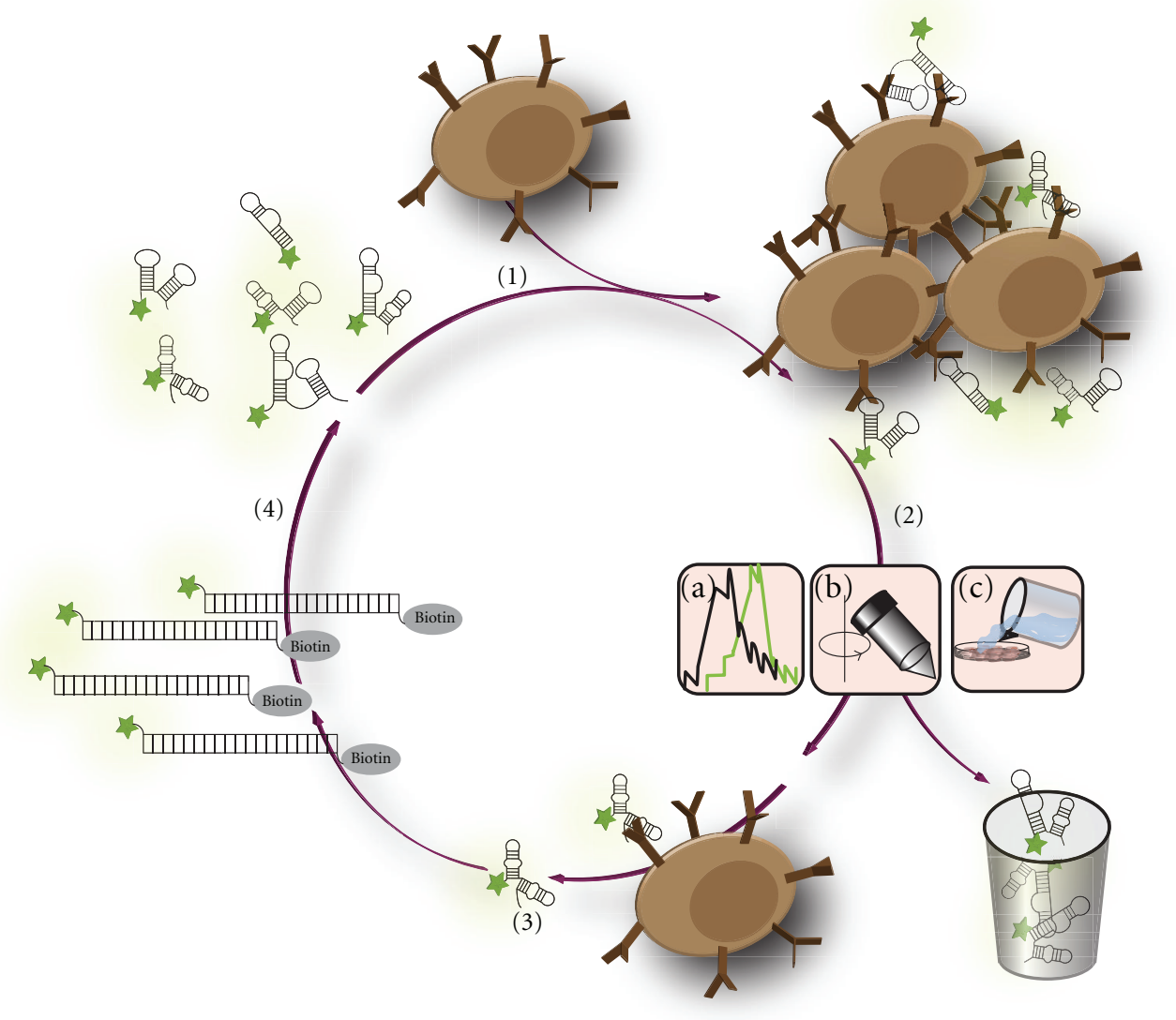

Figure 1: Cell-SELEX. (1) Target cells are incubated with a complex library consisting of up to $10^{15}$ individual single stranded DNA molecules (ssDNA). (2) The separation of cell-binding nucleic acids from nonbinding species can be performed by different methods: FACS (2a), centrifugation (2b) or washing (rinsing) steps (2c), respectively. (3) Cell-binding DNA molecules—aptamers-are eluted and (4) subsequently amplified by PCR using two specific primers. The $5^{\prime}$-end of the reverse primer carries a biotin. Additionally, a fluorescently labeled forward primer is used for PCR, if FACS is used for separation. After strand displacement the enriched DNA library is used for further selection rounds. This cell-SELEX procedure ends up with aptamers that bind specifically to the surface of target cells.

TABLE 1: Cell-lines used for cell-SELEX and for corresponding counter selection. The column "When?" indicates whether counter selection was performed before (B) or after (A) the selection, or not at all (-).

\begin{tabular}{|c|c|c|c|c|c|}
\hline Selection cell line & Abbreviation & Counter selection & Abbreviation & When? & Lit. \\
\hline T-cell line, human ALL & CCRF-CEM & $\begin{array}{l}\text { B-cell line, human Burkitt's } \\
\text { lymphoma }\end{array}$ & Ramos & A & {$[54]$} \\
\hline Carcinoma; small-cell lung cancer & NCI-H69 & Carcinoma; large-cell lung cancer & NCI-H661 & A & {$[55]$} \\
\hline Mouse liver hepatoma cell line & $\begin{array}{l}\text { BNL 1ME A.7R.1 } \\
\text { (MEAR) }\end{array}$ & Normal mouse liver cell line & BNL CL.2 & A & {$[56]$} \\
\hline Acute myeloid leukemia & HL60 & Acute promyelocytic leukemia & NB4 & $\mathrm{A}$ & {$[57]$} \\
\hline $\begin{array}{l}\text { Human lung carcinoma cells } \\
\text { infected with vaccinia virus }\end{array}$ & A549 & $\begin{array}{l}\text { Human lung carcinoma cells } \\
\text { without infection }\end{array}$ & A549 & A & {$[58]$} \\
\hline $\begin{array}{l}\text { Pheochromocytoma of the rat } \\
\text { adrenal medulla expressing } \\
\text { human RET }{ }^{\mathrm{C} 634 \mathrm{Y}} \text { mutant }\end{array}$ & Pc12/MEN2A & $\begin{array}{l}\text { Pheochromocytoma of the rat } \\
\text { adrenal medulla parental cells } \\
\text { followed by cells expressing } \\
\text { human RET } \mathrm{R}^{\mathrm{M} 918 \mathrm{~T}} \text { mutant }\end{array}$ & $\begin{array}{c}\text { Pc12 and } \\
\text { Pc12/MEN2B }\end{array}$ & $\mathrm{B}$ & {$[50]$} \\
\hline $\begin{array}{l}\text { B-cell line, human Burkitt } \\
\text { lymphoma }\end{array}$ & Burkitt lymphoma & $\begin{array}{l}\text { None, but FACS to sort out dead } \\
\text { cells }\end{array}$ & & - & {$[10]$} \\
\hline Human glioblastoma U251 & U251 & None & & - & {$[46]$} \\
\hline Endothelial cell line YPEN-1 & YPEN-1 & N9 microglial cells & & $\mathrm{B}$ & [45] \\
\hline
\end{tabular}


one with adherent Pc12/MEN2B cells before incubating their 2'-F-modified RNA library with Pc12/MEN2A cells, the actual selection target presenting the human $\operatorname{RET}^{\mathrm{C} 634 \mathrm{Y}} \mathrm{mu}-$ tant receptor [50].

Most people who have actively selected aptamers are familiar with the problems of matrix binders. The logic behind this problem is apparent and has been called the first law of directed evolution: "You get what you select for" [51]. Since in every cycle, multiple selection pressures are involved, it is not surprising that artifacts may arise. It can be anticipated that this problem becomes more serious when using complex surfaces of cells or spores as selection target.

To make things even worse, there is an additional problem for cell-SELEX with live cells: in every cell preparation also dead cells are present. Dead cells show strong, sequenceindependent affinity for nucleic acids [52]. They cannot be removed by traditional methods like washing or centrifugation and thus lead at least to an inefficient selection process or even to failure of the experiment [53]. Sample preparation is, therefore, very important. These problems may be the reason why cell-SELEX has not yet become a widely used method for the generation of cell-specific aptamers.

The above issues were addressed in a recent publication by the laboratories of Mayer and Famulok [10]. They used FACS to remove the fraction of dead cells and to select aptamers binding to live cells. Thus, they obtained aptamers specific for B-cells that were able to differentiate between different cell subpopulations.

\section{Cell-Specific Aptamers for Affinity Purification and Diagnostics}

There are numerous applications for aptamers, including aptamers as sensors, as inhibitors, as diagnostics, as therapeutics, and as delivery agents. There are excellent reviews dealing with these topics, for example, [17]. Here, we want to focus on the application of cell-specific aptamers for affinity purification, diagnostics, and most importantly therapy.

The first and obvious application of cell-specific aptamers is their use for affinity purification. Affinity purification has been described with several aptamers selected for single targets $[59,60]$. More interesting purification tools are aptamers with affinity for complex targets like cells. The specific target molecule may be identified afterwards using mass spectrometry.

Using this approach Blank et al. took advantage of an aptamer that binds to tumor microvessels for affinity purification and identified pigpen as the target protein [45]. The above-mentioned aptamer selected for human glioblastoma U251 cells was also used to identify the target protein tenascin-C [46]. An inherent advantage of this aptamerbased target purification-identification approach is that the identified targets are per se addressable.

Tan and coworkers used several of their cell-specific aptamers for extraction of specific cells from complex mixtures. They reported aptamers for small-cell lung cancer (SCLC) cells and used them in conjugates with nanoparticles to isolate and enrich SCLC cells from mixed cell media [55].
The same laboratory developed a method for the rapid collection and detection of leukemia cells based on an aptamer for CCRF-CEM acute leukemia cells and two kinds of nanoparticles (magnetic and fluorescent). This dual approach allowed target cell extraction from complex mix-tures including whole blood samples as well as sensitive cell detection [61].

Aptamers have also a long tradition in classical diagnostic applications, in analogy to antibodies. For the creation of sensors, it is ideal to use a ligand-induced conformational change to create a signal. This has been realized by differential dye binding, fluorescence quenching, FRET, or coupling to different types of nanoparticles. Also, modular aptamer sensors consisting of a recognition domain and a signaling aptamer have been constructed (for a review, see [62]). Re-cently, a sensor based on a cell-specific aptamer was reali-zed by a gold nanoparticle-aptamer conjugate on a lateral flow device that could be used for the detection of Ramos cells [63]. This approach represents first steps towards the de-tection of circulating cancer cells.

\section{Cell-Specific Aptamers for Therapy}

Aptamers are not only a new and promising alternative to antibodies in diagnostics. They may also be used in therapy and medicine. For therapeutic applications, it is of particular interest to selectively deliver drug molecules to disease-related cells or tissues of interest thereby minimizing the exposure of these possibly harmful agents to surrounding healthy tissues. This target-controlled transfer can be achieved by conjugating desired drugs to carriers that specifically interact with components (e.g., proteins) only presented on the surface of pathologically relevant cells. Cell-surface proteins are targeted by more than $60 \%$ of all currently available drugs-underscoring their therapeutic importance [64]. Receptors play the most prominent role among these cell-surface proteins. They receive a signal, transduce it via the cellular membrane, and forward it inside the target cell in many cases to finally trigger a cellular response, such as gene expression.

As mentioned before, cell-SELEX can yield aptamers that are able to interact with specific disease-related proteins on cell surfaces. These aptamers are potential therapeutic compounds because they may cause inhibitory as well as stimulatory effects. Furthermore, most cell-surface proteins undergo recycling processes, such as ligand-induced internalization. This opens new strategies for aptamer-based drugs. Aptamers binding to receptors that are subject to internalization can be infiltrated into target cells, and thus serve as vehicles for desired cargo molecules.

In the following sections, we will give an overview of the current state of cell-specific aptamers. We have classified the aptamers into three categories: aptamers eliciting (i) agonistic or (ii) antagonistic effects on the target protein as well as (iii) aptamers as drug delivering agents.

6.1. Aptamers as Blocking Agents. Aptamers might be of therapeutic relevance due to their inhibitory effects on diseaserelated cell-surface components. One promising approach 
would be the application of aptamers acting on deregulated processes in inflamed tissues or pathological vasculature during angiogenesis.

In 2010, Mann et al. reported phosphorothioate-modified aptamers binding to E-selectin on endothelial cells and above all to the inflamed vasculature of human carcinomas presenting E-selectin in high amounts on their cell surfaces [41]. Selectins comprise a family of calcium-dependent cell adhesion glycoproteins which can be subdivided into 3 groups: E-selectin that can be found in endothelial cells, L-selectin on the surface of leukocytes, and P-selectin on platelets and endothelial cells. All family members play crucial roles during normal and abnormal inflammation processes. Due to structural similarities, they are all able to interact with specific carbohydrates (sialyl Lewis X and sialyl Lewis A) on the surface of leukocytes thereby mediating the contact of the leukocytes to the endothelial wall [70]. E-selectin levels are increased on the endothelial surface of blood vessels within numerous inflammatory diseases, for instance, rheumatoid arthritis and several types of cancer [71]. Therefore, targeting E-selectin in inflamed tissues is a therapeutically highly relevant strategy to prevent cell transmigration processes along endothelial tissues. Mann et al. performed a two-step SELEX procedure (see above). In the first 10 SELEX rounds, purified recombinant E-selectin served as target. Subsequently, the 14 obtained aptamers were screened for binding to E-selectin presented on endothelial cells. Only one of the aptamers named ESTA-1 exhibited binding to cell surface bound E-selectin. Furthermore, this aptamer inhibited the adhesion of sialyl Lewis X positive HL60 cells to E-selectin producing endothelial cells (Figure 2). After intravenous administration, a distinct interaction of the E-selectin-specific aptamers with tumor vasculature could be highlighted in a breast cancer xenograft model [41].

Within the same month Gutsaeva et al. reported on the application of the P-selectin binding RNA aptamer ARC5690 that contained 2 -fluoro pyrimidine and $2^{\prime}$-methoxy purine building blocks for increased nuclease stability. The aptamer effectively blocked the adhesion of circulating sickle red blood cells (RBCs) and leukocytes to endothelial cells in sickle cell disease (SCD) after injection into SCD mice [65]. Administration of the aptamer led to a decreased mortality rate of the treated mice opening the possibility to use these anti-P-selectin aptamers as potential anti-cell adhesion compounds in sickle cell disease.

In 1996, O'Connell et al. succeeded in selecting $2^{\prime}$-aminomodified RNA aptamers binding to L-selectin-Ig chimera (LS-Rg) [37]. The aptamers revealed a calcium-dependent binding to native L-selectin on peripheral blood mononuclear cells (PBMCs). Moreover, the aptamers specifically inhibited the interaction of LS-Rg and of human PBMCs with lymph node high endothelial venules that carry the natural ligands of L-selectin. Nevertheless, there was one significant drawback: the aptamers possessed their highest affinity at $4^{\circ} \mathrm{C}$ and $22^{\circ} \mathrm{C}$. At $37^{\circ} \mathrm{C}$, the affinity for L-selectin was remarkably lower. Thus, these aptamers did not seem to be par-ticularly suitable for in vivo applications [38].
Consequently, Hicke et al. reported on the selection of DNA aptamers that did bind to L-selectin with nanomolar affinity [38]. These aptamers inhibited the L-selectin interaction with sialyl Lewis X. Additionally, the aptamers bound specifically to human L-selectin on lymphocytes and neutrophil cells. The DNAs inhibited lymphocyte rolling on activated endothelial cells in an in vitro flow system. In vivo, the aptamers prevented the homing of human lymphocytes to lymph nodes in severe combined immunodeficiency (SCID) mice.

Aside from adhesion molecules, also cytokines and their respective receptors are involved in a variety of inflammatory diseases like osteoarthritis (OA), the most common degenerative joint disease, caused by cartilage loss in a joint [72]. The cytokine interleukin-17 in conjunction with one of its receptors IL-17R is involved in the pathogenesis of OA. IL$17 \mathrm{R}$ is a glycoprotein that displays a wide tissue distribution and is a central mediator in inflammatory responses [66]. Following IL-17R activation multifunctional cytokines like IL-1 and IL- 6 are produced and enforce infla-mmatory processes. Chen et al. reported on a novel cell-based selection method leading to DNA aptamers specific for IL-17R. The authors used whole IL-17R presenting NIH3T3 cells as targets and unmodified NIH3T3 cells as negative control for counterselection. Aptamer RA10-6 was able to interfere with the interaction of IL-17 and IL-17R in vitro. After intraarticular injections in OA mice the aptamers impeded synovial thickening and inflammation in combination with celecoxib, a small nonsteroidal anti-inflammatory drug (NSAID) often used in the treatment of osteoarthritis. Furthermore, its administration led to a dose-dependent reduction of IL6 levels. In the future, it may be conceivable to additionally administer RA10-6 to NSAIDs in standard therapies for OA to circumvent high NSAID doses and associated side effects.

Aptamers binding to receptor tyrosine kinases (RTKs) also reveal a high therapeutic potential. RTKs are cell surface receptors that bind their ligands like growth factors or hormones with high affinity. Besides their role in the regulation of common cellular processes, such as cell growth and differentiation, RTKs are involved in the development and progression of many cancer types [73]. One example is the human epidermal growth factor receptor-3 (HER3), a member of the type I RTKs. HER3 is catalytically deficient and selfassociates in the absence of its ligand heregulin [74]. After binding of heregulin to HER3, heterodimerization with other RTKs, especially HER2, occurs. Overproduction of both HER2 and HER3 can be found in several types of cancer [75]. Chen et al. were able to select RNA aptamers binding HER3 in its oligomeric state [39]. One aptamer, A30, was further investigated. It did not compete with heregulin for binding to HER3 but inhibited heregulin-dependent tyrosine kinase activity of HER2 and growth of MCF7 cells. Although the inhibition mechanism could not be clarified in detail, this study demonstrates the potential of aptamers as anticancer drugs.

Another RTK used as target for the enrichment of aptamers was the human RET receptor tyrosine kinase [50] (selection see above). One of the obtained aptamers 
TABLE 2: Aptamers with inhibitory function on target molecules and corresponding selection strategies.

\begin{tabular}{|c|c|c|c|}
\hline Target & Aptamer & Selection method & Lit. \\
\hline E-selectin & Thiophosphate-mod. DNA & $\begin{array}{l}\text { Two-step selection using recombinant ES-Ig chimera and } \\
\text { testing on cells as target }\end{array}$ & {$[41]$} \\
\hline P-selectin & $\begin{array}{l}2^{\prime} \text {-amino- and } 2^{\prime} \text {-methoxy-mod. } \\
\text { RNA }\end{array}$ & $\begin{array}{l}\text { Traditional SELEX using recombinant mouse P-selectin as } \\
\text { target }\end{array}$ & {$[65]$} \\
\hline L-selectin & $2^{\prime}$-amino-mod. RNA and DNA & $\begin{array}{l}\text { Traditional SELEX using recombinant L-selectin-Ig chimera } \\
\text { as target }\end{array}$ & {$[37,38]$} \\
\hline IL-17R & DNA & $\begin{array}{l}\text { Cell-SELEX using IL-17R presenting NIH3T3 cells as target, } \\
\text { unmodified NIH3T3 cells for counter selection }\end{array}$ & {$[66]$} \\
\hline HER3 & RNA & $\begin{array}{l}\text { Traditional SELEX using the extracellular part of HER3 as } \\
\text { target }\end{array}$ & {$[39]$} \\
\hline RET & $2^{\prime}$-F-mod. RNA & $\begin{array}{l}\text { Cell-SELEX using RET }{ }^{\mathrm{C} 634 \mathrm{Y}} \text { receptor presenting } \\
\text { Pc12/MEN2A cells as target, Pc12 and Pc12/MEN2B cells for } \\
\text { counterselection }\end{array}$ & {$[50]$} \\
\hline NgR & RNA & $\begin{array}{l}\text { Traditional SELEX using the extracellular part of NgR-Fc } \\
\text { fusion protein as target }\end{array}$ & {$[67]$} \\
\hline CTLA-4 & $2^{\prime}$-F-mod. RNA & Traditional SELEX using CTLA-4-Fc fusion protein as target & {$[68]$} \\
\hline gp120 & $2^{\prime}$-F-mod. RNA & $\begin{array}{l}\text { Traditional SELEX using purified recombinant gp } 120 \text { as } \\
\text { target }\end{array}$ & {$[69]$} \\
\hline
\end{tabular}

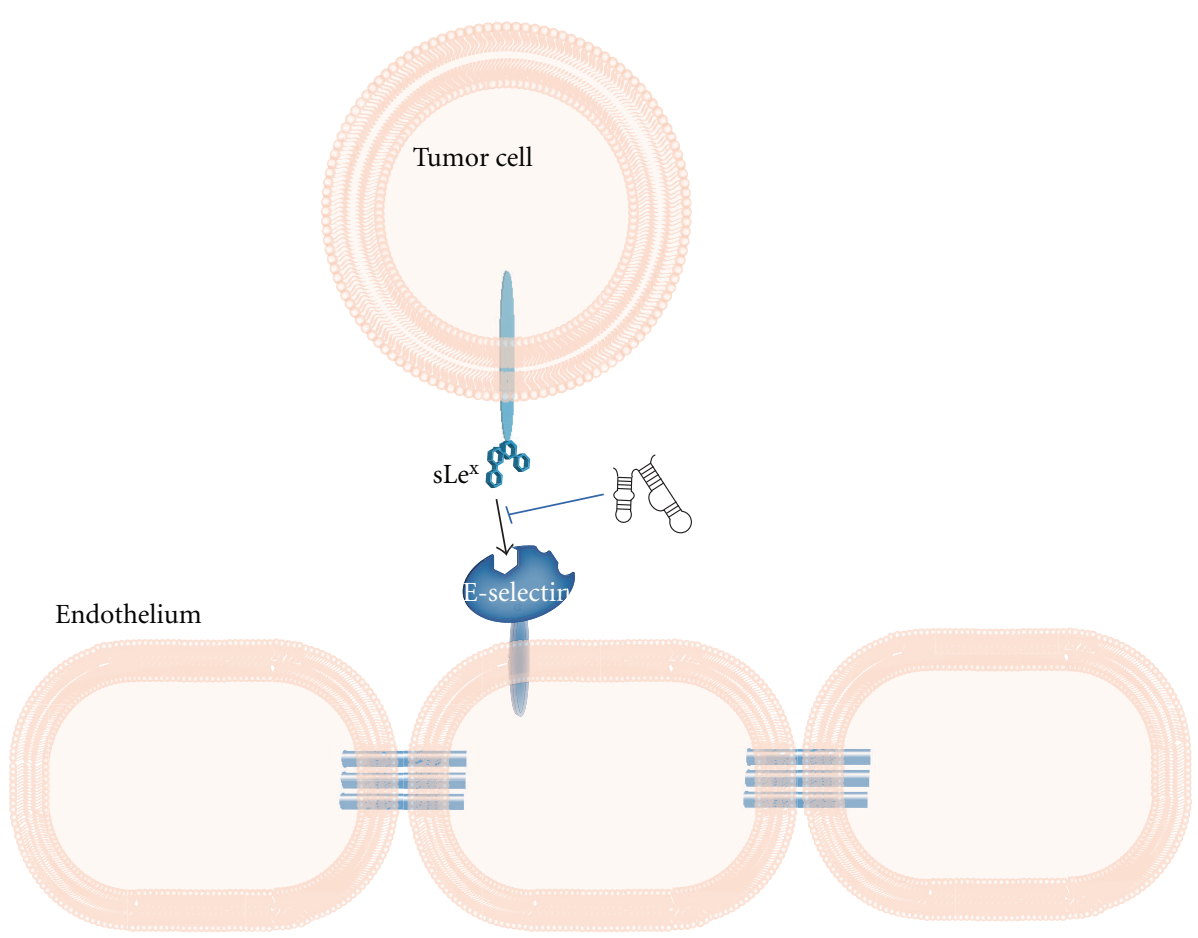

FIGURE 2: Aptamers as blocking agents. Aptamers, in this case composed of phosphorothioates, selectively bind to E-selectin that is presented on the surface of human endothelial cells. The aptamers serve as antagonist for the interaction to sialyl Lewis X on HL-60 cells, a human promyelocytic leukemia cell line, thereby inhibiting the adhesion of tumor cells by more than $75 \%$.

bound to different cell types presenting RET on their cell surface. The aptamer interfered with ligand-induced receptor dimerization or dimerization caused by activating mutations within the receptor, and thereby inhibiting intracellular RET signaling pathways.
In another study, aptamers were used to block the Nogo66 receptor $(\mathrm{NgR})$ on axons after spinal cord injury [67]. Axon regeneration is usually prevented by three inhibitors from the myelin sheath, which are ligands of NgR [76]. The NgR-specific aptamers blocked the myelin-derived inhibitors 
TABLe 3: Aptamers for cell-specific delivery of drug molecules.

\begin{tabular}{|c|c|c|c|}
\hline Target molecule & Aptamer & $\begin{array}{l}\text { Drug molecules linked or complexed with the } \\
\text { aptamer }\end{array}$ & Lit. \\
\hline \multirow[t]{5}{*}{ PSMA } & 2'-F-modified RNA & (1) siRNAs/shRNAs & (1) $[88-92]$ \\
\hline & & (2) Protein toxin gelonin & (2) $[93]$ \\
\hline & & (3) Dox & (3) $[94]$ \\
\hline & & (4) QDs, SPION or gold NPs with Dox & (4) $[95-99]$ \\
\hline & & (5) Pt(IV)-encapsulated PLGA-PEG NPs & (5) $[100]$ \\
\hline gp120 & $2^{\prime}$-F-modified RNA & siRNAs & {$[101,102]$} \\
\hline Nucleolin & DNA & PDT agent TMPyP4 & {$[103]$} \\
\hline PTK7 & DNA & Dox & {$[104]$} \\
\hline $\mathrm{TfR}$ & DNA & L-iduronidase & {$[105]$} \\
\hline MUC1 & DNA & PDT agent chlorin $e_{6}$ & {$[106]$} \\
\hline EGFR & RNA & Gold NPs & {$[107]$} \\
\hline IgM heavy chain & DNA & Micelle-like nanostructures & {$[108]$} \\
\hline
\end{tabular}

by competing for binding to NgR [67] and fostered neurite outgrowth of primary cultured neuronal cells. This result highlights the therapeutic potential of aptamers in the treatment of myelin-associated inhibition of neuronal regeneration.

Santulli-Marotto et al. developed a promising aptamerbased strategy to inhibit the activation of an immune receptor. The authors selected aptamers specific for the Tcell receptor CTLA-4 [68]. CTLA-4 (cytotoxic T lymphocyte antigen-4) is a high affinity receptor for the B7 family members of immune regulatory ligands presented on activated $\mathrm{T}$ cells. This receptor exists in a dimeric form and is stimulated by two molecules of the ligand protein B7-1 [77]. CTLA4 inhibits antitumor immunity. It transmits an inhibitory signal to $\mathrm{T}$ cells, which reduces their ability to respond to stimuli by enhancing the signaling threshold. As a result higher amounts of signal molecules would be required for further stimulation. Inhibitors of CTLA-4 (e.g., antibodies) are potential agents to enhance T-cell anti-tumor immunity [78]. CTLA-4-specific high affinity aptamers enforced tumor immunity in mice [68]. Tetramers of these CTLA-4-binding aptamers showed even stronger inhibitory effects on CTLA4 function in vitro and in vivo. These constructs seem to be useful anti-tumor agents and regulators of the immune system.

Similarly 2 '-F-modified aptamers could be selected with the potential to lower HIV-1 (human immunodeficiency virus 1) infectivity by blocking gp120, a cell surface receptor, both, on HIV-1 and on HIV-1 infected immune cells [69, 79, 80]. Further developments and applications will be discussed later.

6.2. Aptamers as Stimulating Agents. In this section we will focus on aptamers causing activating effects by binding to therapeutically relevant cell-surface proteins.

Recently, McNamara et al. introduced agonistic aptamers specific for the costimulatory receptor 4-1BB, a member of the tumor necrosis factor (TNF) receptor family [81]. This receptor is presented on activated $\mathrm{CD}^{+}$T-cells and pro-

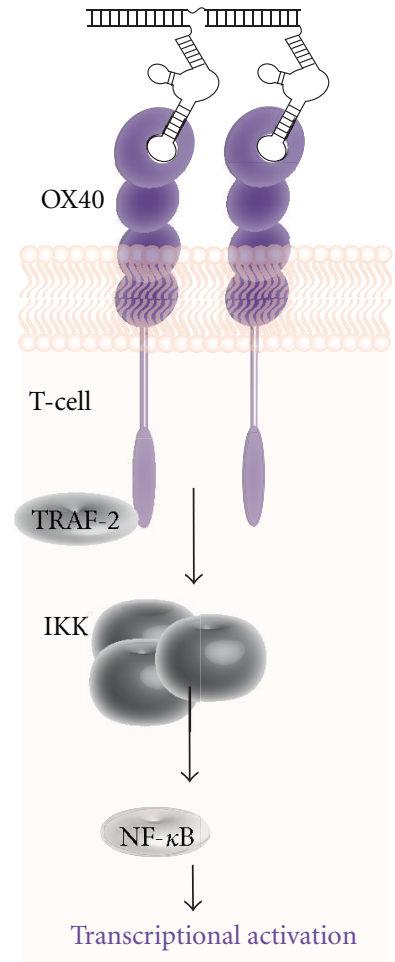

FIGURE 3: Aptamers as stimulating agents. Dimerized OX40-specific RNA aptamers show activating effects on the OX40 receptor in vitro and in vivo. The OX40 receptor on the surface of activated $\mathrm{T}$ cells undergoes receptor oligomerization and provides a costimulatory signal for T cell activation. Downstream factors (e.g., TRAF-2, IKK and $\mathrm{NF}-\kappa \mathrm{B}$ ) of the signaling cascade are activated leading to an enhanced proliferation of T cells and an increased anti-tumor immune response.

longs the survival and expansion of $\mathrm{CD}^{+} \mathrm{T}$ lymphocytes [82]. Since $\mathrm{CD}^{+}$T-cells play an important role in tumor immunity, enhancing 4-1BBs costimulatory activity could support anti-tumor immune responses. Indeed, agonistic 
monoclonal antibodies against 4-1BB that had been systemically administered to mice ameliorated tumor immunity and tumor rejection [83, 84]. Aptamers for 4-1BB represent an attractive alternative because antibodies can be immunogenic in some cases and might cause problems in clinical trials. The aptamers specifically bound to $4-1 \mathrm{BB}$ presented on the surface of activated $T$ cells [81]. Stimulation of receptors of the TNF receptor family, including 4-1BB, often involves oligomerization. Notably, the oligomerization could be induced by dimeric and multimeric forms of the aptamers and triggered the activation of $4-1 \mathrm{BB}$. Thus, the aptamerbased di- and multimers acquired the ability to costimulate $\mathrm{T}$ cells and induce tumor rejection in mice. As mentioned above, there are aptamers that block CTLA- 4 functions on activated T-cells in vivo and enforce tumor immunity in mice [68]. Combinations of aptamers for CTLA-4 and 4-1BB may even be better antitumor agents than each aptamer by itself.

Dollins et al. extended the approach of inducing receptor multimerization by aptamers to trigger agonistic effects. They selected aptamers for the target molecule OX40 [40]. OX40, another member of the TNF receptor family, is presented on the surface of activated T cells. Binding of its ligand OX40L (OX40 ligand) causes receptor oligomerization. This activation leads to an enhanced proliferation rate of $\mathrm{T}$ cells, to an increased cytokine production, and to an intensified anti-tumor immune response. After selection, Dollins et al. converted the monomeric aptamers into receptor activating dimers using a molecular scaffold (Figure 3 ). This aptamer complex mimicked the OX40 ligand and induced OX40 multimerization and function both in vitro and in vivo in a tumor immunotherapy approach. Systemic administration of the agonistic aptamer complex showed a remarkable effect in the treatment of highly metastatic and aggressive types of melanoma [40]. Both the 4-1BB and the OX40 aptamers impressively demonstrated how cell-surface receptor binding aptamers could be turned into receptor activating complexes by di- or multimerization $[40,81]$. These nucleic acid-based agonists could become a new safe and powerful class of therapeutically relevant effectors.

A related approach combined two DNA aptamers for different tumor associated targets [85]. Boltz et al. described the generation of chimeric DNA aptamers that simultaneously bound two surface receptors of immune cells and mediated tumor lysis.

Specifically, one of the aptamers bound to the $\mathrm{Fc} y$ receptor IIIA also known as CD16 $\alpha$. CD16 $\alpha$ belongs to the immunoglobulin superfamily and is mostly presented on natural killer cells but also on monocytes and certain tissue macrophages, respectively. CD16 $\alpha$ plays an important role during the antibody-dependent cellular cytotoxicity (ADCC). The recruitment of CD16 $\alpha$-positive NK-cells to specific tumor cells could increase the antitumor-effective function during ADCC. The second aptamer bound to the hepatocyte growth factor receptor (HGF-R) also known as c-Met. The c-Met receptor belongs to the RTK family. As mentioned above, RTKs are important regulators in cellular processes and thus key players in the development and progression of many cancer types [86]. The c-Met protein is presented on epithelial cells, important for embryonic development and overproduced in many tumors $[85,86]$. Aptamers recognizing both, the CD16 $\alpha$ and c-Met could potentially recruit NK-cells to c-Met-positive tumor cells, inducing ADCC and, therefore, acting as anti-tumor agents. Boltz et al. generated high-affinity aptamers for CD16 $\alpha$ and for c-Met and connected them by an oligonucleotide linker. The resulting bi-specific aptamers mediated cellular cytotoxicity, induced killing of NK cells and subsequently specifically lysed tumor cells in ADCC assays. In the future, the authors will expand these findings to in vivo experiments using xenograft mouse models. Taken together the described bi-specific aptamers illustrate the ability of nucleic acidbased therapeutics to stimulate the lysis of tumor cells, a property that opens up the possibility to serve as reagents in cancer therapy.

6.3. Aptamers for Delivery of Toxic Payloads. Aptamers can also serve as modules that selectively recognize and bind to defined cell types or tissues. By appending drug molecules, the aptamers can be used to deliver cargo molecules to or into specific cells or tissues of interest.

6.3.1. Prostate Specific Membrane Antigen (PSMA). One of the best-studied aptamers binds to the prostate specific membrane antigen (PSMA), a well-known tumor marker for prostate cancer [87].

In 2002, Lupold et al. reported the selection of $2^{\prime}-\mathrm{F}-$ modified RNA aptamers binding to the extracellular portion of PSMA. Aptamer A10 and its truncated version A10-3 were able to bind PSMA presenting human prostate cancer cells with high affinity and served as a prostate specific tumor cell marker [8]. The detection of specific endocytosis of PSMA into cells via clathrin-coated pits suggested that PSMA-specific aptamers might be potential drug delivery vehicles [109]. Therefore, aptamer-drug chimeras were constructed. The idea was that the aptamers would specifically recognize and bind to prostate cancer cells and then become endocytosed together with PSMA—resulting in drug delivery to the target cells.

Several groups created chimeras consisting of small interfering RNAs (siRNAs) and the PSMA-specific aptamer A10 [88-91]. McNamara et al. used a completely RNA-based approach by directly connecting the PSMA aptamer A10 at its $3^{\prime}$-end with therapeutic siRNAs specific for plk 1 and $b c l$ 2 , two survival genes that are overexpressed in many human tumors [89] (Figure 4). The chimeras were supposed to bind PSMA on target cells via the aptamer and to silence the target mRNAs via the siRNA portions. Administration of the chimeras to PSMA presenting cells indeed resulted in endocytosis, gene silencing, reduced cell proliferation, and finally cell death. Importantly, the chimeras did not affect cells that did not present PSMA. The next step was the intratumoral application of the aptamer-siRNA chi-meras into athymic mice that carried tumors derived from PSMApositive human prostate cancer cells. In these mice, the chimeras indeed reduced tumor growth. The same experiment was performed with mice bearing tumors from PSMAnegative human prostate cancer cells. These tumors were 


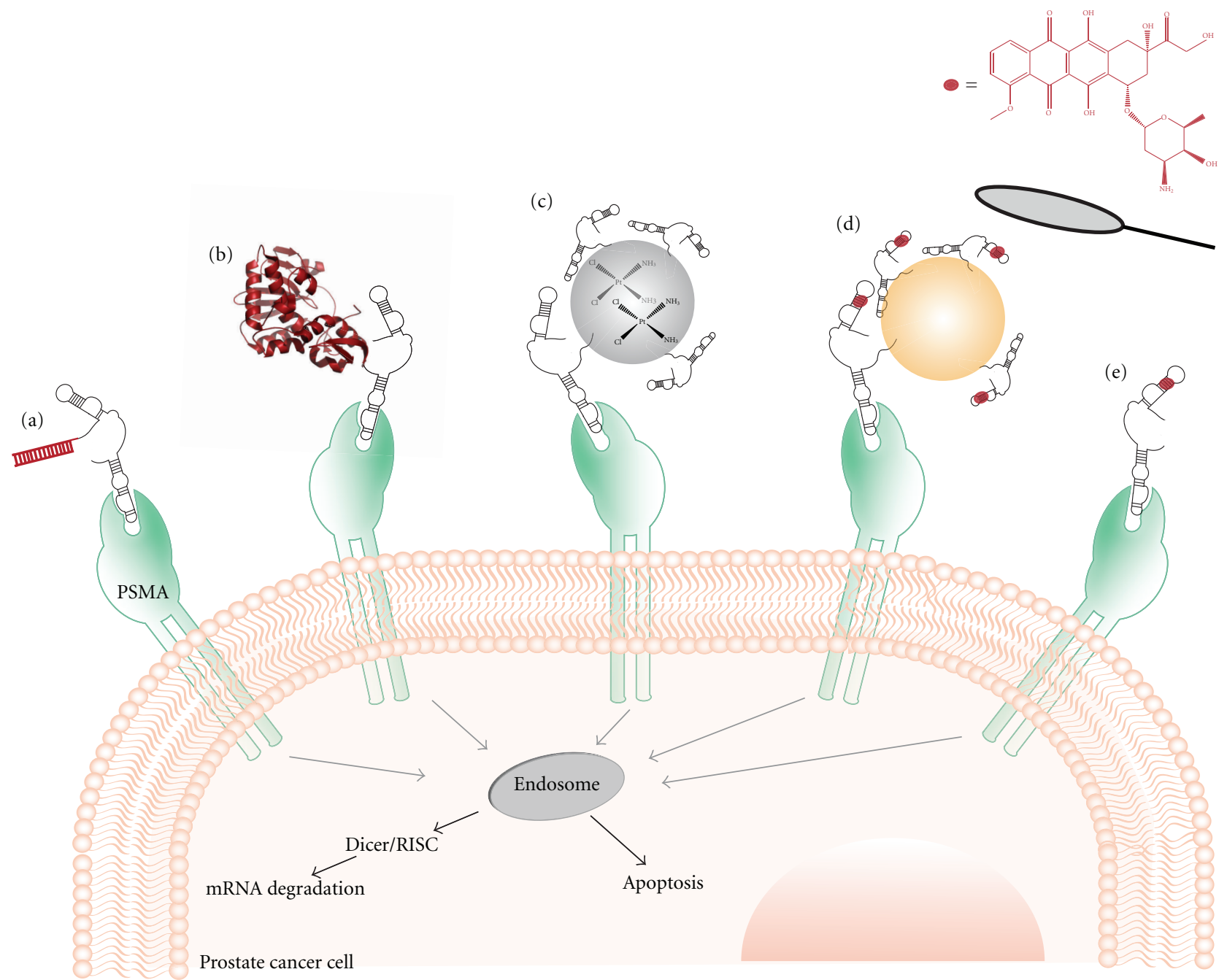

FIGURE 4: Aptamers as drug delivery agents. Prostate specific membrane antigen (PSMA) is internalized into cells via endocytosis. PSMAbinding RNA aptamers serve as drug delivery vehicles for small interfering RNAs (siRNAs, (a)). The siRNAs escape from the endosome, are processed by Dicer and RISC, and lead to the degradation of target mRNAs. Furthermore, the aptamers can escort cytotoxic molecules into prostate cancer cells like the ribosomal toxin gelonin (b), cisplatin encapsulated in organic PLGA-PEG-NPs (c), nanoparticles (NPs, gold, iron oxide and quantum dots; (d)), or doxorubicin as a physical conjugate (e). For references see text.

not affected by the chimeras. This strongly suggests that the cellular uptake of the RNA ligands was highly efficient and specific for PSMA. The aptamer-siRNA chimeras were further optimized by the same group [90]. The authors truncated the aptamer portion and enhanced the silencing activity and specificity by incorporating modifications within the siRNA molecules leading to a more efficient processing effectivity of the RNAi machinery. The optimized chimeras were systemically administered into athymic mice bearing tumors from PSMA-positive human prostate cancer cells leading to distinct tumor regression or anti-tumor activity, respectively.

Chu et al. used another conjugation strategy between a PSMA-specific aptamer and two different siRNAs specific for lamin A/C or GAPDH (Glyceraldehyde 3-phosphate dehydrogenase) mRNAs [91]. Both the aptamer and the siRNAs were chemically modified with biotin and bound to tetrameric streptavidin in a $2: 2: 1$ ratio. The resulting RNAprotein complexes were cell type-specifically internalized and caused down regulation of target genes and cell-death of PSMA-presenting cancer cells. Wullner et al. created multivalent aptamer-siRNA constructs to further increase potency and anti-tumor capacity of the chimeras [88]. The authors generated two different bivalent chimeras consisting of the anti-PSMA aptamer and siRNA specific for the EEF2 (eukaryotic elongation factor 2) mRNA. In one case, the siRNA itself served as linker between two aptamer molecules, whereas in the other case, siRNAs were attached to the $3^{\prime}$ end of each aptamer. The increased valency of the aptamersiRNA chimeras enhanced cytotoxicity with respect to the monovalent counterparts.

Very recently, Ni et al. used aptamer-shRNA chimeras to inhibit DNA repair pathways in prostate cancer cells and subsequently to enhance ionizing radiation (IR) therapy 
[92]. The target mRNA of the shRNA was the catalytic subunit of DNAPK (DNA-activated protein kinase, catalytic polypeptide). DNAPK is a serine/threonine protein kinase that is necessary for the double-strand break repair in DNA [110]. Therefore, downregulation of DNAPK by aptamershRNA chimeras should selectively sensitize PSMA-positive cells to IR. Cell-specific delivery of the aptamer-shRNA chimeras to PSMA-positive LNCaP cells and to tumor models led to reduced levels of DNAPK mRNA [92]. A combination of the application of aptamer-shRNA chimeras and IR for the treatment of LNCaP tumor models resulted in an extended reduction of tumor volume due to enhanced radiosensitivity. Finally, the authors could also demonstrate high efficacy of the chimeras in human prostate tissue.

Apart from aptamer chimeras with siRNA, aptamers can be fused to toxic proteins to deliver them into target cells. This approach was realized by covalently linking a PSMAspecific aptamer [93] to a gelonin derivative (Figure 4). Gelonin is a ribosome-tackling toxin that cleaves a specific glycosidic bond in rRNA subsequently disrupting protein biosynthesis. This gelonin derivative lacks the translocational domain and, in contrast to related toxins, is not translocated per se into cells. In conjunction with the aptamer, however, the gelonin variant was internalized into PSMA-presenting tumor cells consequently destroying them. This unequivocally demonstrated the ability of the PSMA-aptamer to deliver a therapeutically relevant toxin as payload into target cells.

Chemotherapeutic drugs represent another class of drug molecules that had been successfully delivered into PSMApositive human prostate cancer cells via the aptamer A10 [94, 95, 100]. Bagalkot et al. produced physical aptamer-doxorubicin conjugates not requiring any chemical modification neither of the drug nor of the aptamer [94] (Figure 4). Doxorubicin (Dox) can intercalate into the aptamer portion. Dox is an anthracycline-derived drug molecule used in chemotherapy to treat a wide range of cancers. Since this treatment causes many side effects, targeted delivery would be desirable to decrease doses and associated cytotoxicities. The authors studied in vitro binding and cell-specific uptake of the physical conjugates by the PSMA-positive prostate cancer cell line LNCaP to evaluate the targeted drug delivery. A significant reduction of the cell proliferation as well as enhanced cytotoxicity occurred in comparison to control cells [94].

The same group immobilized the PSMA-specific aptamer A10 on the surface of fluorescent quantum dots (QDs). Additionally, the A10-derivatized QDs were incubated with Dox yielding QD-A10-Dox conjugates [97] (Figure 4). Although not covalently linked, the aptamer-Dox-complex quenched the fluorescence of the QDs. When incubated with target cells these multifunctional nanoparticle conjugates de-livered Dox into PSMA-positive cells. Cellular uptake could be detected due to the recovered fluorescence emission of the QDs that subsequently stained the corresponding can-cer cells. Additionally, Dox inhibited the growth of those cells.

In related approaches, superparamagnetic iron oxide nanoparticles (SPION) or gold nanoparticles were derivatized with A10 and Dox to create multifunctional nanoparticle conjugates for both imaging and treatment of prostate cancer cells $[98,99]$. Each of the three parts of the conjugates had a distinct function: the aptamer portion served as delivery vehicle, the nanoparticle served as platform and imaging agent in magnetic resonance imaging (MRI) or computer tomography (CT), and Dox served as toxin (Figure 4).

The physical conjugates, however, were only able to carry a limited amount of cargo molecules. A new strategy with higher capacity was therefore developed by Bagalkot et al. [94]. This group produced biocompatible and biodegradable nanoparticles (NPs) derived from poly(D,L-lactic-co-glycolic acid)-block-poly(ethylene glycol) (PLGA-b-PEG) copolymers. The surface of the NPs was coated with the PSMAspecific aptamer A10. The authors encapsulated the antimitotic chemotherapy drug docetaxel (Dtxl) into the NPs, resulting in Dtxl-containing nanoparticle-aptamer bioconjugates (Dtxl-NP-Apt). Treating LNCaP prostate cancer cells with Dtxl-NP-Apt led to a specific uptake by these cells and furthermore to a significant enhancement of cytotoxicity in vitro in comparison to nanoparticles lacking A10. Intratumoral injection of the bioconjugates into LNCaP-derived tumors in xenograft nude mice diminished tumor growth in five out of seven mice.

Dhar et al. encapsulated the cisplatin prodrug Pt(IV) within PLGA-PEG nanoparticles that were coated with the PSMA aptamer A10 [100] (Figure 4). After cell-specific uptake of the Pt(IV)-NP-Apt bioconjugates, Pt(IV) was converted by cytosolic reduction processes into cisplatin. Cytotoxicity assays with LNCaP cells revealed a higher in vitro cytotoxic activity for the $\mathrm{Pt}(\mathrm{IV})$-NP-Apt bioconjugates with respect to free cisplatin or bioconjugates lacking the aptamer portion. Additionally, the same laboratory recently analyzed the pharmacokinetics, biodistribution, tolerability, and efficiency of the Pt(IV)-NP-Apt bioconjugates when administered in vivo in comparison to cisplatin [95]. The authors observed a simultaneous improvement of all these factors and proved the bioconjugates to be an efficient nontoxic item for chemotherapeutic treatment of human prostate cancer.

6.3.2. Glycoprotein 120 (gp120). Envelope glycoprotein gp160 of HIV-1, consisting of two parts, gp120 (glycoprotein 120) and gp41 (glycoprotein 41), respectively, plays a crucial role in HIV-1 infection. Therefore, blocking HIV-1 entry into $\mathrm{T}$ cells with the aid of corresponding aptamers seems to be a therapeutically promising strategy. James et al. reported the selection of 2'-F-modified RNA aptamers that bound to gp120 with high affinity, and thereby neutralized the infectivity of R5 strains of HIV-1 in human peripheral blood mononuclear cells (PBMCs) by blocking the interaction between gp120 and CCR5 $[69,79,80]$. Zhou et al. published in 2008 the application of these RNA aptamers [101]. The authors designed aptamer-siRNA-chimeras that bound and entered target cells via gp160-mediated endocytosis. The siRNA portions were processed by dicer and specifically downregulated the mRNA levels of the HIV-transcripts tat and rev. This was the first report on aptamer-siRNA-chimera in which both parts inhibited HIV-1 functions. 
One year later, the same group published the selection of new 2'-F-modified gp120-binding aptamers that blocked HIV-1 infection of cultured CEM T cells. Aptamers were endocytosed into gp160-presenting target cells [102]. The authors again took advantage of the cell-specific delivery process of gp120-binding agents. Application of optimized aptamer-siRNA-chimeras resulted in a successful downregulation of tat- and rev-mRNAs, thereby reducing HIV-1 replication and infectivity in PBMCs. Taken together, the antigp120 aptamers may be promising agents for an anti-HIV therapy due to their ability to inhibit HIV-1 infectivity and replication or due to their potential to escort further drugs into affected cells.

6.3.3. Nucleolin. Nucleolin, a multifunctional eukaryotic nucleolar phosphoprotein, plays a pivotal role in RNA transcription, in DNA replication, and in the regulation of different steps of ribosome biogenesis [111]. Furthermore nucleolin binds to the mRNA of Bcl-2, an antiapoptotic protein overproduced in several cancer types, and thereby increasing its half-life [112]. Nucleolin is overproduced in the cytoplasm and on the plasma membrane of certain tumor cells [113]. AS1411, a $26 \mathrm{nt}$ long nucleolin-binding DNA aptamer, is taken up by nucleolin-presenting cancer cells and prevents interaction of nucleolin with the mRNA of the antiapoptotic Bcl-2. This causes destabilization of the Bcl-2 mRNA and subsequently a reduction of Bcl-2 protein which may cause apoptosis [114]. Phase I and II clinical trials have revealed the potency of AS1411 as new therapeutic agent of different cancer types, like relapsed or refractory acute myeloid leukemia or renal cell carcinoma [113].

To further improve AS1411 functions, Shieh et al. tested in 2010 whether AS1411 could deliver drugs to target cancer cells for photodynamic therapy (PDT) [103]. They created physical conjugates of AS1411 and TMPyP4 (5,10,15,20tetrakis(1-methylpyridinium-4-yl)porphyrin). TMPyP4 is a photosensitizing porphyrin derivative that interacts with Gquadruplexes. Intracellularly, it serves as potent inhibitor of human telomerase [115]. The physical complex was escorted into MCF7 breast cancer cells and normal endothelial M10 cells via aptamer-mediated delivery and caused TMPyP4 accumulation in MCF7 cells but not in M10 cells. Subsequently, both cell types were exposed to light. The MCF7 cells were damaged to a significantly higher extent than the control cells. These results underscore the potential of AS1411 as a drug-delivery agent in cancer therapy.

6.3.4. Tyrosine-Protein Kinase-Like 7 Enzyme. Using cellSELEX, Shangguan et al. selected numerous different aptamers that specifically recognized leukemia cells [54] (details in cell-SELEX chapter). For the cell-SELEX experiment the authors targeted cultured CCRF-CEM cells, a precursor cell line of $\mathrm{T}$ cell acute lymphoblastic leukemia cells (ALL). Ramos cells, a B cell line from human Burkitt's lymphoma, served for counter selection. Resulting aptamers specifically recognized CCRF-CEM cells with high affinity. Furthermore, target leukemia cells were identified when mixed with patients' human bone marrow aspirates. After identification of PTK7 (Tyrosine-protein kinase-like 7) as target molecule of $\operatorname{sgc} 8$, Xiao et al. chose the aptamer $\operatorname{sgc} 8 \mathrm{c}$ for further cell-specific internalization studies [116]. Several drug-like molecules were loaded on $\mathrm{sgc} 8 \mathrm{c}$, for instance, the MS2-coat protein [117] or the chemotherapeutic agents daunorubicin [118] and doxorubicin [104]. A conjugate of the latter with the aptamer $\operatorname{sgc} 8$ was particularly efficient in selectively killing specific cancer cells.

6.3.5. Transferrin Receptor (TfR). The enzyme replacement therapy (ERT) is a therapeutic application to replace an absent or deficient enzyme in patients by a functional counterpart. ERT is used for example in lysosomal storage diseases [119]. Receptors that underlie endocytosis are highly relevant for escort of these lysosomal enzymes into cells if coupled to appropriate delivery vehicles like aptamers. One of the mentioned receptors is TfR, ubiquitously presented on mammalian cells. It directs iron to cells via binding of transferrin- $\mathrm{Fe}^{3+}$, followed by cellular endocytosis and iron release into the endosomes [120]. Chen et al. used both, DNA and RNA aptamers, selectively binding to the mouse transferrin receptor (TfR) [105]. RNA aptamers for TfR were first coupled to streptavidin. The conjugates bound specifically to mouse fibroblasts ( $\mathrm{Ltk}^{-}$cells) but not to human 293T cells. Streptavidin could be detected in the lysosomes of $\mathrm{Ltk}^{-}$cells presumably due to cellular uptake via endocytosis. After this proof of principle, a DNA aptamer was linked to $\alpha$-L-iduronidase, a lysosomal enzyme [105]. Cells lacking this enzyme accumulate glycosaminoglycan. The aptamerenzyme conjugates were internalized into mouse fibroblasts deficient for $\alpha$-L-iduronidase and mediated by the TfR-specific DNA aptamer. The $\alpha$-L-iduronidase was delivered into lysosomes. Inside the lysosome, the enzyme could counteract the glycosaminoglycan accumulation. The results reveal the potency of aptamers to escort lysosomal enzymes into target cells-a first step towards an aptamer-mediated enzyme replacement therapy for lysosomal storage diseases [105].

6.3.6. Mucin-1 (MUC1). Mucin-1 (MUC1) is a glycoprotein with considerable O-glycosylation within its extracellular domain. Membrane-associated glycoforms of MUC1 uniquely and abundantly line the cell surfaces of most epithelial cells, for instance, eyes, lungs and intestines. MUC1 represents an important surface biomarker for early diagnosis of cancers [121, 122]. MUC1 tumor markers undergo recycling processes, for instance, through endosomes. Therefore, these cell surface proteins may serve as entry portals for aptamers specifically binding to MUC1. Ferreira et al. reported recently the selection of MUC1 binding DNA aptamers using mimics of well-known MUC1 determinants on cancer cells as target molecules [123]. The obtained aptamers interacted specifically with cells presenting MUC1 glycosylation forms and were efficiently internalized by epithelial cancer cells. Coupling the aptamers to prodrugs like chlorin $e_{6}$ (Ce6), a heme-like agent for photodynamic therapy (PDT), selectively killed MUC1 presenting epithelial cancer cell lines [106].

6.3.7. Epidermal Growth Factor Receptor (EGFR). The epidermal growth factor receptor (EGFR) is a transmembrane 
receptor with intrinsic tyrosine kinase activity. The EGFR belongs to a family of receptors known as the ErbB family (ErbB tyrosine kinase receptors). EGFR functions in a wide range of cellular processes, including cell proliferation and apoptosis [124]. It is overproduced in some types of cancer cells [125]. EGFR is activated upon binding to its ligands, for instance, EGF (epidermal growth factor) and TGF $\alpha$ (transforming growth factor). Subsequently, EGFR changes from an inactive monomeric form to an active homodimeric form leading to autophosphorylation and signal transduction. EGFR activation triggers internalization processes suggesting that receptor binding aptamers could become cointernalized, and thus serve as drug-delivery tools [126]. Li et al. reported in 2010 on the selection and application of aptamers that bind specifically to EGFR [107]. The authors generated conjugates of aptamers and gold nanoparticles that specifically targeted EGFR presenting A431 cells. The A431 cells internalized the aptamer-coated gold nanoparticles via EGFR-mediated endocytosis. Presumably, these aptamers are suitable for the delivery of further cargo molecules into EGFR presenting cells.

6.3.8. Immunglobulin M Heavy Chain. In 2007, Tang et al. reported on the cell-based systematic evolution of aptamers binding whole living cells [127]. Ramos cells, a B-cell Burkitt's lymphoma cell line, served as target in the cellSELEX process. Resulting aptamers were able to identify Ramos cells within a complex biological mixture [127]. On the basis of this work, Mallikaratchy et al. identified membrane protein targets that were bound by the Ramos cell-specific aptamers [128]. By covalently cross-linking the Ramos cell-specific aptamer TD05 to its target cells, the authors could identify the molecular target of TD05 using mass spectrometry: the membrane bound IgM heavy chain. It is part of the B-cell receptor and presented in high amounts on the surface of Burkitt's lymphoma cells. Internalization of the aptamer, however, was not shown.

Nevertheless, converting these aptamers into delivery agents $\mathrm{Wu}$ et al. published a novel approach by modifying the end of an aptamer with a hydrophobic tail [108]. This resulted in the assembly of highly ordered micelle-like nanoparticles.

These aptamer-containing nanoparticles showed lower off rates after binding to the Ramos cells at $37^{\circ} \mathrm{C}$, presumably due to multivalency. Furthermore, assembly of the aptamers to micelles allows them to enter their target cells by fusion of the micelle with the membrane of target cells. Loading the micelles with drugs could thus yield drug delivery agents. Additionally, the authors mimicked blood circulation of living organisms in a flow channel system. The aptamermicelles were still able to recognize their target under flow conditions. These results might pave the way for further applications of aptamer-micelles as drug-delivery vehicles in a biological living system.

\section{Conclusions}

Since the invention of the SELEX process more than two decades ago, considerable progress has been made in the field of aptamer technology. Several improvements, most importantly automation, have made the traditional SELEX procedure faster and more efficient and aptamers more easily available. Aptamers for all kinds of targets, ranging from small molecules to cell surface receptors have successfully been selected. Today, the selection of aptamers for whole cells is becoming increasingly popular, because their ability to specifically recognize subpopulations of cells is highly sought after. We anticipate that recent technical advances will further boost this trend. In particular, the use of FACS in the selection step represents a major technical progress, as it allows selecting aptamers and removing selection-hampering dead cells simultaneously.

The characteristics of aptamers also make them promising tools for diagnostic applications. Aptamer-based arrays, for example, could become a valuable alternative to antibody-based microarrays for protein production profiling of whole cells. These aptamer arrays might also be used to identify a specific cell type in complex cell mixtures. However, more time and scientific effort will still be required before aptamer-based products for diagnostics will be routinely applied.

Aptamers also have numerous properties that render them promising tools in therapy. As reviewed in this paper, there are aptamers for a large variety of cell-specific target molecules that play crucial roles in diseases, like viral infection, inflammation, and cancer. We have summarized examples from the recent literature illustrating aptamers that inhibit or activate cellular functions. Furthermore, we outlined how aptamers have been used to deliver therapeutic agents, such as chemotherapeutics, siRNAs or nanoparticles to cells or tissues. Aptamers are formidable delivery tools, because they are comparatively small and can easily penetrate tissues or become cointernalized with the receptors they are specifically binding to. Furthermore, aptamers can be tuned for desired applications: modified bases can be integrated to increase the in vivo stability or to regulate their in vivo function. The possibility to regulate and control the function of aptamers is crucial for a defined application in therapy. In this field, we expect further developments based on light regulation of aptamers as has been demonstrated by caged aptamers for human thrombin [129]. Another promising approach is the use of activatable [130] and deactivatable [129] aptamer probes (AAP) for the targeting of membrane proteins of living cancer cells [131].

Most of the diagnostically und therapeutically relevant aptamers mentioned in this paper have so far only been tested in animal models. There is only a limited number of clinical investigations of aptamers for therapeutic applications in humans. Some of these aptamers are binding specifically to defined proteins in cancer and eye diseases. However, even if there is only one FDA-approved aptamerbased drug so far (Macugen), some additional aptamers have already entered the phase of clinical trials. This is not very astonishing, because it often takes more than 10 years before a drug candidate becomes commercially available. The timeline for the development of aptamers as commercial therapeutics is comparable to the generation of antibodybased drugs. In 1975, the first monoclonal antibodies were 
generated. In 1986, the first monoclonal antibody was approved by the FDA for therapeutically application the second one in 1994. The same holds true for aptamersin 1990, the first aptamers were selected, in 2004, the first aptamer-based drug, Macugen, was approved by the FDA.

Finally, the selection of aptamers and their use in diagnostic and therapeutic applications is still an expanding area. Presumably, in the near future, further aptamers may become approved drugs.

\section{References}

[1] A. D. Ellington and J. W. Szostak, "In vitro selection of RNA molecules that bind specific ligands," Nature, vol. 346, no. 6287, pp. 818-822, 1990.

[2] C. Tuerk and L. Gold, "Systemic evolution of ligands by exponential enrichment: RNA ligands to bacteriophage T4 DNA polymerase," Science, vol. 249, no. 4968, pp. 505-510, 1990.

[3] D. L. Robertson and G. F. Joyce, "Selection in vitro of an RNA enzyme that specifically cleaves single-stranded DNA," Nature, vol. 344, no. 6265, pp. 467-468, 1990.

[4] L. A. Holeman, S. L. Robinson, J. W. Szostak, and C. Wilson, "Isolation and characterization of fluorophore-binding RNA aptamers," Folding and Design, vol. 3, no. 6, pp. 423-431, 1998.

[5] K. Harada and A. D. Frankel, "Identification of two novel arginine binding DNAs," EMBO Journal, vol. 14, no. 23, pp. 5798-5811, 1995.

[6] H. Schürer, K. Stembera, D. Knoll et al., "Aptamers that bind to the antibiotic moenomycin A," Bioorganic and Medicinal Chemistry, vol. 9, no. 10, pp. 2557-2563, 2001.

[7] S. D. Mendonsa and M. T. Bowser, "In vitro selection of aptamers with affinity for neuropeptide Y using capillary electrophoresis," Journal of the American Chemical Society, vol. 127, no. 26, pp. 9382-9383, 2005.

[8] S. E. Lupold, B. J. Hicke, Y. Lin, and D. S. Coffey, "Identification and characterization of nuclease-stabilized RNA molecules that bind human prostate cancer cells via the prostatespecific membrane antigen," Cancer Research, vol. 62, no. 14, pp. 4029-4033, 2002.

[9] Z. Balogh, G. Lautner, V. Bardóczy, B. Komorowska, R. E. Gyurcsányi, and T. Mészáros, "Selection and versatile application of virus-specific aptamers," FASEB Journal, vol. 24, no. 11, pp. 4187-4195, 2010.

[10] M. S. L. Raddatz, A. Dolf, E. Endl, P. Knolle, M. Famulok, and G. Mayer, "Enrichment of cell-targeting and populationspecific aptamers by fluorescence-activated cell sorting," Angewandte Chemie International Edition, vol. 47, no. 28, pp. 5190-5193, 2008.

[11] S. D. Jayasena, "Aptamers: an emerging class of molecules that rival antibodies in diagnostics," Clinical Chemistry, vol. 45, no. 9, pp. 1628-1650, 1999.

[12] A. D. Keefe, S. Pai, and A. Ellington, "Aptamers as therapeutics," Nature Reviews Drug Discovery, vol. 9, no. 7, pp. 537$550,2010$.

[13] P. R. Bouchard, R. M. Hutabarat, and K. M. Thompson, "Discovery and development of therapeutic aptamers," Annual Review of Pharmacology and Toxicology, vol. 50, pp. 237-257, 2010.

[14] E. W. M. Ng, D. T. Shima, P. Calias, E. T. Cunningham, D. R. Guyer, and A. P. Adamis, "Pegaptanib, a targeted anti-VEGF aptamer for ocular vascular disease," Nature Reviews Drug Discovery, vol. 5, no. 2, pp. 123-132, 2006.

[15] G. R. Zimmermann, R. D. Jenison, C. L. Wick, J. P. Simorre, and A. Pardi, "Interlocking structural motifs mediate molecular discrimination by a theophylline-binding RNA," Nature Structural Biology, vol. 4, no. 8, pp. 644-649, 1997.

[16] P. L. Sazani, R. Larralde, and J. W. Szostak, "A small aptamer with strong and specific recognition of the triphosphate of ATP," Journal of the American Chemical Society, vol. 126, no. 27, pp. 8370-8371, 2004.

[17] M. Famulok, J. S. Hartig, and G. Mayer, "Functional aptamers and aptazymes in biotechnology, diagnostics, and therapy," Chemical Reviews, vol. 107, no. 9, pp. 3715-3743, 2007.

[18] R. Yamamoto, M. Katahira, S. Nishikawa, T. Baba, K. Taira, and P. K. R. Kumar, "A novel RNA motif that binds efficiently and specifically to the Tat protein of HIV and inhibits the trans-activation by Tat of transcription in vitro and in vivo," Genes to Cells, vol. 5, no. 5, pp. 371-388, 2000.

[19] L. Giver, D. Bartel, M. Zapp, A. Pawul, M. Green, and A. D. Ellington, "Selective optimization of the Rev-binding element of HIV-1," Nucleic Acids Research, vol. 21, no. 23, pp. 5509-5516, 1993.

[20] K. A. Whitehead, R. Langer, and D. G. Anderson, "Knocking down barriers: advances in siRNA delivery," Nature Reviews Drug Discovery, vol. 8, no. 2, pp. 129-138, 2009.

[21] R. Juliano, M. R. Alam, V. Dixit, and H. Kang, "Mechanisms and strategies for effective delivery of antisense and siRNA oligonucleotides," Nucleic Acids Research, vol. 36, no. 12, pp. 4158-4171, 2008.

[22] M. G. Theis, A. Knorre, B. Kellersch et al., "Discriminatory aptamer reveals serum response element transcription regulated by cytohesin-2," Proceedings of the National Academy of Sciences of the United States of America, vol. 101, no. 31, pp. 11221-11226, 2004.

[23] Y. Liu, C. T. Kuan, J. Mi et al., "Aptamers selected against the unglycosylated EGFRvIII ectodomain and delivered intracellularly reduce membrane-bound EGFRvIII and induce apoptosis," Biological Chemistry, vol. 390, no. 2, pp. 137-144, 2009.

[24] L. Chaloin, M. J. Lehmann, G. Sczakiel, and T. Restle, "Endogenous expression of a high-affinity pseudoknot RNA aptamer suppresses replication of HIV-1," Nucleic Acids Research, vol. 30, no. 18, pp. 4001-4008, 2002.

[25] K. H. Choi, M. W. Park, S. Y. Lee et al., "Intracellular expression of the T-cell factor-1 RNA aptamer as an intramer," Molecular Cancer Therapeutics, vol. 5, no. 9, pp. 2428-2434, 2006.

[26] J. Mi, X. Zhang, Z. N. Rabbani et al., "H1 RNA polymerase III promoter-driven expression of an RNA aptamer leads to high-level inhibition of intracellular protein activity," Nucleic Acids Research, vol. 34, no. 12, pp. 3577-3584, 2006.

[27] G. Mayer, M. Blind, W. Nagel et al., "Controlling small guanine-nucleotide-exchange factor function through cytoplasmic RNA intramers," Proceedings of the National Academy of Sciences of the United States of America, vol. 98, no. 9, pp. 4961-4965, 2001.

[28] M. Hafner, A. Schmitz, I. Grüne et al., "Inhibition of cytohesins by SecinH3 leads to hepatic insulin resistance," Nature, vol. 444, no. 7121, pp. 941-944, 2006.

[29] A. Rhie, L. Kirby, N. Sayer et al., "Characterization of 2'fluoro-RNA aptamers that bind preferentially to diseaseassociated conformations of prion protein and inhibit conversion," Journal of Biological Chemistry, vol. 278, no. 41, pp. 39697-39705, 2003. 
[30] N. C. Pagratis, C. Bell, Y. F. Chang et al., "Potent 2'-amino-, and 2'-fluoro-2'-deoxyribonucleotide RNA inhibitors of keratinocyte growth factor," Nature Biotechnology, vol. 15, no. 1, pp. 68-73, 1997.

[31] J. Ruckman, L. S. Green, J. Beeson et al., “2'-fluoropyrimidine RNA-based aptamers to the 165-amino acid form of vascular endothelial growth factor (VEGF165): inhibition of receptor binding and VEGF-induced vascular permeability through interactions requiring the exon 7-encoded domain," Journal of Biological Chemistry, vol. 273, no. 32, pp. 20556-20567, 1998.

[32] P. E. Burmeister, S. D. Lewis, R. F. Silva et al., "Direct in vitro selection of a 2'-O-methyl aptamer to VEGF," Chemistry and Biology, vol. 12, no. 1, pp. 25-33, 2005.

[33] D. Shangguan, Z. Cao, L. Meng et al., "Cell-specific aptamer probes for membrane protein elucidation in cancer cells," Journal of Proteome Research, vol. 7, no. 5, pp. 2133-2139, 2008.

[34] K. T. Guo, A. Paul, C. Schichor, G. Ziemer, and H. P. Wendel, "Cell-SELEX: novel perspectives of aptamer-based therapeutics," International Journal of Molecular Sciences, vol. 9, no. 4, pp. 668-678, 2008.

[35] L. Cerchia and V. de Franciscis, "Targeting cancer cells with nucleic acid aptamers," Trends in Biotechnology, vol. 28, no. 10, pp. 517-525, 2010.

[36] K. N. Morris, K. B. Jensen, C. M. Julin, M. Weil, and L. Gold, "High affinity ligands from in vitro selection: complex targets," Proceedings of the National Academy of Sciences of the United States of America, vol. 95, no. 6, pp. 2902-2907, 1998.

[37] D. O'Connell, A. Koenig, S. Jennings et al., "Calcium-dependent oligonucleotide antagonists specific for L-selectin," Proceedings of the National Academy of Sciences of the United States of America, vol. 93, no. 12, pp. 5883-5887, 1996.

[38] B. J. Hicke, S. R. Watson, A. Koenig et al., "DNA aptamers block L-selectin function in vivo: inhibition of human lymphocyte trafficking in SCID mice," Journal of Clinical Investigation, vol. 98, no. 12, pp. 2688-2692, 1996.

[39] C. H. B. Chen, G. A. Chernis, V. Q. Hoang, and R. Landgraf, "Inhibition of heregulin signaling by an aptamer that preferentially binds to the oligomeric form of human epidermal growth factor receptor-3," Proceedings of the National Academy of Sciences of the United States of America, vol. 100, no. 16, pp. 9226-9231, 2003.

[40] C. M. Dollins, S. Nair, D. Boczkowski et al., "Assembling OX40 aptamers on a molecular scaffold to create a receptoractivating aptamer," Chemistry and Biology, vol. 15, no. 7, pp. 675-682, 2008.

[41] A. P. Mann, A. Somasunderam, R. Nieves-Alicea et al., "Identification of thioaptamer ligand against E-selectin: potential application for inflamed vasculature targeting," PLoS ONE, vol. 5, no. 9, article e13050, pp. 1-11, 2010.

[42] B. J. Hicke, C. Marion, Y. F. Chang et al., "Tenascin-C aptamers are generated using tumor cells and purified pro-tein," Journal of Biological Chemistry, vol. 276, no. 52, pp. 4864448654, 2001.

[43] M. Homann and H. U. Göringer, "Combinatorial selection of high affinity RNA ligands to live African trypanosomes," Nucleic Acids Research, vol. 27, no. 9, pp. 2006-2014, 1999.

[44] J. G. Bruno and J. L. Kiel, "In vitro selection of DNA aptamers to anthrax spores with electrochemiluminescence detection," Biosensors and Bioelectronics, vol. 14, no. 5, pp. 457-464, 1999.

[45] M. Blank, T. Weinschenk, M. Priemer, and H. Schluesener, "Systematic evolution of a DNA aptamer binding to rat brain tumor microvessels: selective targeting of endothelial regulatory protein pigpen," Journal of Biological Chemistry, vol. 276, no. 19, pp. 16464-16468, 2001.

[46] D. A. Daniels, H. Chen, B. J. Hicke, K. M. Swiderek, and L. Gold, "A tenascin-C aptamer identified by tumor cell SELEX: systematic evolution of ligands by exponential enrichment," Proceedings of the National Academy of Sciences of the United States of America, vol. 100, no. 26, pp. 15416-15421, 2003.

[47] K. Sefah, D. Shangguan, X. Xiong, M. B. O'Donoghue, and W. Tan, "Development of DNA aptamers using Cell-SELEX," Nature Protocols, vol. 5, no. 6, pp. 1169-1185, 2010.

[48] J. C. Cox, A. Hayhurst, J. Hesselberth, T. S. Bayer, G. Georgiou, and A. D. Ellington, "Automated selection of aptamers against protein targets translated in vitro: from gene to aptamer," Nucleic Acids Research, vol. 30, no. 20, p. e108, 2002.

[49] R. K. Mosing and M. T. Bowser, "Isolating aptamers using capillary electrophoresis-SELEX (CE-SELEX)," Methods in Molecular Biology, vol. 535, pp. 33-43, 2009.

[50] L. Cerchia, F. Ducongé, C. Pestourie et al., "Neutralizing aptamers from whole-cell SELEX inhibit the RET receptor tyrosine kinase.," PLoS Biology, vol. 3, no. 4, article e123, 2005.

[51] H. Zhao and F. H. Arnold, "Directed evolution converts subtilisin E into a functional equivalent of thermitase," Protein Engineering, vol. 12, no. 1, pp. 47-53, 1999.

[52] M. Avci-Adali, M. Metzger, N. Perle, G. Ziemer, and H. P. Wendel, "Pitfalls of cell-systematic evolution of ligands by exponential enrichment (SELEX): existing dead cells during in vitro selection anticipate the enrichment of specific aptamers," Oligonucleotides, vol. 20, no. 6, pp. 317-323, 2010.

[53] G. Mayer, M. S. L. Ahmed, A. Dolf, E. Endl, P. A. Knolle, and M. Famulok, "Fluorescence-activated cell sorting for aptamer SELEX with cell mixtures," Nature Protocols, vol. 5, no. 12, pp. 1993-2004, 2010.

[54] D. Shangguan, Y. Li, Z. Tang et al., "Aptamers evolved from live cells as effective molecular probes for cancer study," Proceedings of the National Academy of Sciences of the United States of America, vol. 103, no. 32, pp. 11838-11843, 2006.

[55] H. W. Chen, C. D. Medley, K. Sefah et al., "Molecular recognition of small-cell lung cancer cells using aptamers," ChemMedChem, vol. 3, no. 6, pp. 991-1001, 2008.

[56] D. Shangguan, L. Meng, Z. C. Cao et al., "Identification of liver cancer-specific aptamers using whole live cells," Analytical Chemistry, vol. 80, no. 3, pp. 721-728, 2008.

[57] K. Sefah, Z. W. Tang, D. H. Shangguan et al., "Molecular recognition of acute myeloid leukemia using aptamers," Leukemia, vol. 23, no. 2, pp. 235-244, 2009.

[58] Z. Tang, P. Parekh, P. Turner, R. W. Moyer, and W. Tan, "Generating aptamers for recognition of virus-infected cells," Clinical Chemistry, vol. 55, no. 4, pp. 813-822, 2009.

[59] C. Srisawat and D. R. Engelke, "Streptavidin aptamers: affinity tags for the study of RNAs and ribonucleoproteins," RNA, vol. 7, no. 4, pp. 632-641, 2001.

[60] T. S. Romig, C. Bell, and D. W. Drolet, "Aptamer affinity chromatography: combinatorial chemistry applied to protein purification," Journal of Chromatography B, vol. 731, no. 2, pp. 275-284, 1999.

[61] J. K. Herr, J. E. Smith, C. D. Medley, D. Shangguan, and W. Tan, "Aptamer-conjugated nanoparticles for selective collection and detection of cancer cells," Analytical Chemistry, vol. 78, no. 9, pp. 2918-2924, 2006.

[62] A. Rentmeister and M. Famulok, "Functional nucleic acid sensors as screening tools," in Functional Nucleic Acids for 
Analytical Applications, L. Yingfu and L. Yi, Eds., p. 343, Springe, New York, NY, USA, 2003.

[63] G. Liu, X. Mao, J. A. Phillips, H. Xu, W. Tan, and L. Zeng, "Aptamer-nanoparticle strip biosensor for sensitive detection of cancer cells," Analytical Chemistry, vol. 81, no. 24, pp. 10013-10018, 2009.

[64] J. P. Overington, B. Al-Lazikani, and A. L. Hopkins, "How many drug targets are there?" Nature Reviews Drug Discovery, vol. 5, no. 12, pp. 993-996, 2006.

[65] D. R. Gutsaeva, J. B. Parkerson, S. D. Yerigenahally et al., "Inhibition of cell adhesion by anti-P-selectin aptamer: a new potential therapeutic agent for sickle cell disease," Blood, vol. 117, no. 2, p. 727, 2011.

[66] L. Chen, D. Q. Li, J. Zhong et al., "IL-17RA aptamer-mediated repression of IL-6 inhibits synovium inflammation in a murine model of osteoarthritis," Osteoarthritis Cartilage, vol. 19, no. 6, p. 711, 2011.

[67] Y. Wang, Z. Z. Khaing, N. Li et al., "Aptamer antagonists of myelin-derived inhibitors promote axon growth," PLoS ONE, vol. 5, no. 3, article e9726, 2010.

[68] S. Santulli-Marotto, S. K. Nair, C. Rusconi, B. Sullenger, and E. Gilboa, "Multivalent RNA aptamers that Inhibit CTLA-4 and enhance tumor immunity," Cancer Research, vol. 63, no. 21, pp. 7483-7489, 2003.

[69] M. Khati, M. Schüman, J. Ibrahim, Q. Sattentau, S. Gordon, and W. James, "Neutralization of infectivity of diverse R5 clinical isolates of human immunodeficiency virus type 1 by gp120-binding 2'F-RNA aptamers," Journal of Virology, vol. 77, no. 23, pp. 12692-12698, 2003.

[70] T. A. Springer, "Traffic signals for lymphocyte recirculation and leukocyte emigration: the multistep paradigm," Cell, vol. 76, no. 2, pp. 301-314, 1994.

[71] S. R. Barthel, J. D. Gavino, L. Descheny, and C. J. Dimitroff, "Targeting selectins and selectin ligands in inflammation and cancer," Expert Opinion on Therapeutic Targets, vol. 11, no. 11, pp. 1473-1491, 2007.

[72] M. C. Honorati, M. Bovara, L. Cattini, A. Piacentini, and A. Facchini, "Contribution of interleukin 17 to human cartilage degradation and synovial inflammation in osteoarthritis," Osteoarthritis and Cartilage, vol. 10, no. 10, pp. 799-807, 2002.

[73] E. Zwick, J. Bange, and A. Ullrich, "Receptor tyrosine kinase signalling as a target for cancer intervention strategies," Endocrine-Related Cancer, vol. 8, no. 3, pp. 161-173, 2001.

[74] H. S. Cho and D. J. Leahy, "Structure of the extracellular region of HER3 reveals an interdomain tether," Science, vol. 297, no. 5585, pp. 1330-1333, 2002.

[75] G. Krähn, U. Leiter, P. Kaskel et al., "Coexpression patterns of EGFR, HER2, HER3 and HER4 in non-melanoma skin cancer," European Journal of Cancer, vol. 37, no. 2, pp. 251-259, 2001.

[76] F. Hu, B. P. Liu, S. Budel et al., "Nogo-A interacts with the Nogo-66 receptor through multiple sites to create an isoform-selective subnanomolar agonist," Journal of Neuroscience, vol. 25, no. 22, pp. 5298-5304, 2005.

[77] C. C. Stamper, Y. Zhang, J. F. Tobin et al., "Crystal structure of the B7-1/CTLA-4 complex that inhibits human immune responses," Nature, vol. 410, no. 6828, p. 608, 2001.

[78] D. R. Leach, M. F. Krummel, and J. P. Allison, "Enhancement of antitumor immunity by CTLA-4 blockade," Science, vol. 271, no. 5256, pp. 1734-1736, 1996.

[79] A. K. Dey, M. Khati, M. Tang, R. Wyatt, S. M. Lea, and W. James, "An aptamer that neutralizes R5 strains of human immunodeficiency virus type 1 blocks gp120-CCR5 interaction," Journal of Virology, vol. 79, no. 21, pp. 13806-13810, 2005.

[80] A. K. Dey, C. Griffiths, S. M. Lea, and W. James, "Structural characterization of an anti-gp120 RNA aptamer that neutralizes R5 strains of HIV-1," RNA, vol. 11, no. 6, pp. 873-884, 2005.

[81] J. O. McNamara, D. Kolonias, F. Pastor et al., "Multivalent 41BB binding aptamers costimulate CD8+ T cells and inhibit tumor growth in mice," Journal of Clinical Investigation, vol. 118, no. 1, pp. 376-386, 2008.

[82] H. W. Lee, S. J. Park, B. K. Choi, H. H. Kim, K. O. Nam, and B. S. Kwon, "4-1BB promotes the survival of CD8+ T lymphocytes by increasing expression of Bcl-xL and Bfl-1," Journal of Immunology, vol. 169, no. 9, pp. 4882-4888, 2002.

[83] I. Melero, W. W. Shuford, S. A. Newby et al., "Monoclonal antibodies against the 4-1BB T-cell activation molecule eradicate established tumors," Nature Medicine, vol. 3, no. 6, pp. 682-685, 1997.

[84] K. F. May Jr., L. Chen, P. Zheng, and Y. Liu, "Anti-4-1BB monoclonal antibody enhances rejection of large tumor burden by promoting survival but not clonal expansion of tumor-specific CD8+ T cells," Cancer Research, vol. 62, no. 12, pp. 3459-3465, 2002.

[85] A. Boltz, B. Piater, L. Toleikis et al., "Bi-specific aptamers mediating tumour cell lysis," The Journal of Biological Chemistry, vol. 268, no. 24, pp. 21896-21905, 2011.

[86] J. P. Eder, G. F. Vande Woude, S. A. Boerner, and P. M. Lorusso, "Novel therapeutic inhibitors of the c-Met signaling pathway in cancer," Clinical Cancer Research, vol. 15, no. 7, pp. 2207-2214, 2009.

[87] M. I. Davis, M. J. Bennett, L. M. Thomas, and P. J. Bjorkman, "Crystal structure of prostate-specific membrane antigen, a tumor marker and peptidase," Proceedings of the National Academy of Sciences of the United States of America, vol. 102, no. 17, pp. 5981-5986, 2005.

[88] U. Wullner, I. Neef, A. Eller, M. Kleines, M. K. Tur, and S. Barth, "Cell-specific induction of apoptosis by rationally designed bivalent aptamer-siRNA transcripts silencing eukaryotic elongation factor 2," Current Cancer Drug Targets, vol. 8, no. 7, pp. 554-565, 2008.

[89] J. O. McNamara, E. R. Andrechek, Y. Wang et al., "Cell typespecific delivery of siRNAs with aptamer-siRNA chimeras," Nature Biotechnology, vol. 24, no. 8, pp. 1005-1015, 2006.

[90] J. P. Dassie, X. Y. Liu, G. S. Thomas et al., "Systemic administration of optimized aptamer-siRNA chimeras promotes regression of PSMA-expressing tumors," Nature Biotechnology, vol. 27, no. 9, pp. 839-846, 2009.

[91] T. C. Chu, K. Y. Twu, A. D. Ellington, and M. Levy, "Aptamer mediated siRNA delivery," Nucleic Acids Research, vol. 34, no. 10, article e73, 2006.

[92] X. Ni, Y. Zhang, J. Ribas et al., "Prostate-targeted radiosensitization via aptamer-shRNA chimeras in human tumor xenografts," The Journal of Clinical Investigation, vol. 121, no. 6, p. 2383, 2011.

[93] T. C. Chu, J. W. Marks, L. A. Lavery et al., "Aptamer:toxin conjugates that specifically target prostate tumor cells," Cancer Research, vol. 66, no. 12, pp. 5989-5992, 2006.

[94] V. Bagalkot, O. C. Farokhzad, R. Langer, and S. Jon, "An aptamer-doxorubicin physical conjugate as a novel targeted drug-delivery platform," Angewandte Chemie International Edition, vol. 45, no. 48, pp. 8149-8152, 2006. 
[95] S. Dhar, N. Kolishetti, S. J. Lippard, and O. C. Farokhzad, "Targeted delivery of a cisplatin prodrug for safer and more effective prostate cancer therapy in vivo," Proceedings of the National Academy of Sciences of the United States of America, vol. 108, no. 5, p. 1850, 2011.

[96] O. C. Farokhzad, J. Cheng, B. A. Teply et al., "Targeted nanoparticle-aptamer bioconjugates for cancer chemotherapy in vivo," Proceedings of the National Academy of Sciences of the United States of America, vol. 103, no. 16, pp. 6315-6320, 2006.

[97] V. Bagalkot, L. Zhang, E. Levy-Nissenbaum et al., "Quantum dot-aptamer conjugates for synchronous cancer imaging, therapy, and sensing of drug delivery based on Bi-fluorescence resonance energy transfer," Nano Letters, vol. 7, no. 10, pp. 3065-3070, 2007.

[98] A. Z. Wang, V. Bagalkot, C. C. Vasilliou et al., "Superparamagnetic iron oxide nanoparticle-aptamer bioconjugates for combined prostate cancer imaging and therapy," ChemMedChem, vol. 3, no. 9, pp. 1311-1315, 2008.

[99] D. Kim, Y. Y. Jeong, and S. Jon, "A drug-loaded aptamer-gold nanoparticle bioconjugate for combined ct imaging and therapy of prostate cancer," ACS Nano, vol. 4, no. 7, pp. 36893696, 2010.

[100] S. Dhar, F. X. Gu, R. Langer, O. C. Farokhza, and S. J. Lippard, "Targeted delivery of cisplatin to prostate cancer cells by aptamer functionalized Pt(IV) prodrug-PLGA - PEG nanoparticles," Proceedings of the National Academy of Sciences of the United States of America, vol. 105, no. 45, pp. 1735617361, 2008.

[101] J. Zhou, H. Li, S. Li, J. Zaia, and J. J. Rossi, "Novel dual inhibitory function aptamer-siRNA delivery system for HIV-1 therapy," Molecular Therapy, vol. 16, no. 8, pp. 1481-1489, 2008.

[102] J. Zhou, P. Swiderski, H. Li et al., "Selection, characterization and application of new RNA HIV gp 120 aptamers for facile delivery of Dicer substrate siRNAs into HIV infected cells," Nucleic Acids Research, vol. 37, no. 9, pp. 3094-3109, 2009.

[103] Y. A. Shieh, S. J. Yang, M. F. Wei, and M. J. Shieh, "Aptamerbased tumor-targeted drug delivery for photodynamic therapy," ACS Nano, vol. 4, no. 3, pp. 1433-1442, 2010.

[104] Y. F. Huang, D. Shangguan, H. Liu et al., "Molecular assembly of an aptamer-drug conjugate for targeted drug delivery to tumor cells," ChemBioChem, vol. 10, no. 5, pp. 862-868, 2009.

[105] C. H. B. Chen, K. R. Dellamaggiore, C. P. Ouellette et al., "Aptamer-based endocytosis of a lysosomal enzyme," Proceedings of the National Academy of Sciences of the United States of America, vol. 105, no. 41, pp. 15908-15913, 2008.

[106] C. S. M. Ferreira, M. C. Cheung, S. Missailidis, S. Bisland, and J. Gariépy, "Phototoxic aptamers selectively enter and kill epithelial cancer cells," Nucleic Acids Research, vol. 37, no. 3, pp. 866-876, 2009.

[107] N. Li, T. Larson, H. H. Nguyen et al., "Directed evolution of gold nanoparticle delivery to cells," Chemical Communications, vol. 46, no. 3, p. 392, 2010.

[108] Y. Wu, K. Sefah, H. Liu, R. Wang, and W. Tan, "DNA aptamer-micelle as an efficient detection/delivery vehicle toward cancer cells," Proceedings of the National Academy of Sciences of the United States of America, vol. 107, no. 1, pp. 5-10, 2010.

[109] H. Liu, P. Moy, S. Kim et al., "Monoclonal antibodies to the extracellular domain of prostate-specific membrane antigen also react with tumor vascular endothelium," Cancer Research, vol. 57, no. 17, pp. 3629-3634, 1997.
[110] U. Moll, R. Lau, M. A. Sypes, M. M. Gupta, and C. W. Anderson, "DNA-PK, the DNA-activated protein kinase, is differentially expressed in normal and malignant human tissues," Oncogene, vol. 18, no. 20, pp. 3114-3126, 1999.

[111] H. Ginisty, F. Amalric, and P. Bouvet, "Nucleolin functions in the first step of ribosomal RNA processing," EMBO Journal, vol. 17, no. 5, pp. 1476-1486, 1998.

[112] D. Ishimaru, L. Zuraw, S. Ramalingam et al., "Mechanism of regulation of bcl-2 mRNA by nucleolin and A+U-rich element-binding factor 1 (AUF1)," Journal of Biological Chemistry, vol. 285, no. 35, pp. 27182-27191, 2010.

[113] S. Soundararajan, L. Wang, V. Sridharan et al., "Plasma membrane nucleolin is a receptor for the anticancer aptamer AS1411 in MV4-11 leukemia cells," Molecular Pharmacology, vol. 76, no. 5, pp. 984-991, 2009.

[114] S. Soundararajan, W. Chen, E. K. Spicer, N. CourtenayLuck, and D. J. Fernandes, "The nucleolin targeting aptamer AS1411 destabilizes Bcl-2 messenger RNA in human breast cancer cells," Cancer Research, vol. 68, no. 7, pp. 2358-2365, 2008.

[115] S. Y. Rha, E. Izbicka, R. Lawrence et al., "Effect of telomere and telomerase interactive agents on human tumor and normal cell lines," Clinical Cancer Research, vol. 6, no. 3, pp. 987993, 2000.

[116] Z. Xiao, D. Shangguan, Z. Cao, X. Fang, and W. Tan, "Cellspecific internalization study of an aptamer from whole cell selection," Chemistry, vol. 14, no. 6, pp. 1769-1775, 2008.

[117] G. J. Tong, S. C. Hsiao, Z. M. Carrico, and M. B. Francis, "Viral capsid DNA aptamer conjugates as multivalent celltargeting vehicles," Journal of the American Chemical Society, vol. 131, no. 31, pp. 11174-11178, 2009.

[118] S. M. Taghdisi, K. Abnous, F. Mosaffa, and J. Behravan, “Targeted delivery of daunorubicin to T-cell acute lymphoblastic leukemia by aptamer," Journal of Drug Targeting, vol. 18, no. 4, pp. 277-281, 2010.

[119] R. J. Desnick and E. H. Schuchman, "Enzyme replacement and enhancement therapies: lessons from lysosomal disorders," Nature Reviews Genetics, vol. 3, no. 12, pp. 954-966, 2002.

[120] A. Dautry Varsat, A. Ciechanover, and H. F. Lodish, "pH and the recycling of transferrin during receptor-mediated endocytosis," Proceedings of the National Academy of Sciences of the United States of America, vol. 80, no. 8 I, pp. 2258-2262, 1983.

[121] A. K. H. Cheng, H. Su, Y. A. Wang, and H. Z. Yu, "Aptamerbased detection of epithelial tumor marker mucin 1 with quantum dot-based fluorescence readout," Analytical Chemistry, vol. 81, no. 15, pp. 6130-6139, 2009.

[122] M. A. Hollingsworth and B. J. Swanson, "Mucins in cancer: protection and control of the cell surface," Nature Reviews Cancer, vol. 4, no. 1, pp. 45-60, 2004.

[123] C. S. M. Ferreira, C. S. Matthews, and S. Missailidis, "DNA aptamers that bind to MUC1 tumour marker: design and characterization of MUC1-binding single-stranded DNA aptamers,” Tumor Biology, vol. 27, no. 6, pp. 289-301, 2006.

[124] A. B. Singh and R. C. Harris, "Autocrine, paracrine and juxtacrine signaling by EGFR ligands," Cellular Signalling, vol. 17, no. 10, pp. 1183-1193, 2005.

[125] M. Ono and M. Kuwano, "Molecular mechanisms of epidermal growth factor receptor (EGFR) activation and response to gefitinib and other EGFR-targeting drugs," Clinical Cancer Research, vol. 12, no. 24, pp. 7242-7251, 2006.

[126] S. Sigismund, E. Argenzio, D. Tosoni, E. Cavallaro, S. Polo, and P. P. Di Fiore, "Clathrin-mediated internalization is 
essential for sustained EGFR signaling but dispensable for degradation," Developmental Cell, vol. 15, no. 2, pp. 209-219, 2008.

[127] Z. Tang, D. Shangguan, K. Wang et al., "Selection of aptamers for molecular recognition and characterization of cancer cells," Analytical Chemistry, vol. 79, no. 13, pp. 4900-4907, 2007.

[128] P. Mallikaratchy, Z. Tang, S. Kwame, L. Meng, D. Shangguan, and W. Tan, "Aptamer directly evolved from live cells recognizes membrane bound immunoglobin heavy mu chain in Burkitt's lymphoma cells," Molecular \& Cellular Proteomics, vol. 6, no. 12, pp. 2230-2238, 2007.

[129] A. Heckel, M. C. R. Buff, M. S. L. Raddatz et al., "An anticoagulant with light-triggered antidote activity," Angewandte Chemie International Edition, vol. 45, no. 40, p. 6748, 2006.

[130] A. Heckel and G. Mayer, "Light regulation of aptamer activity: an anti-thrombin aptamer with caged thymidine nucleobases," Journal of the American Chemical Society, vol. 127, no. 3, pp. 822-823, 2005.

[131] H. Shi, X. X. He, K. M. Wang et al., "Activatable aptamer probe for contrast-enhanced in vivo cancer imaging based on cell membrane protein-triggered conformation alteration," Proceedings of the National Academy of Sciences of the United States of America, vol. 108, no. 10, p. 3900, 2011. 

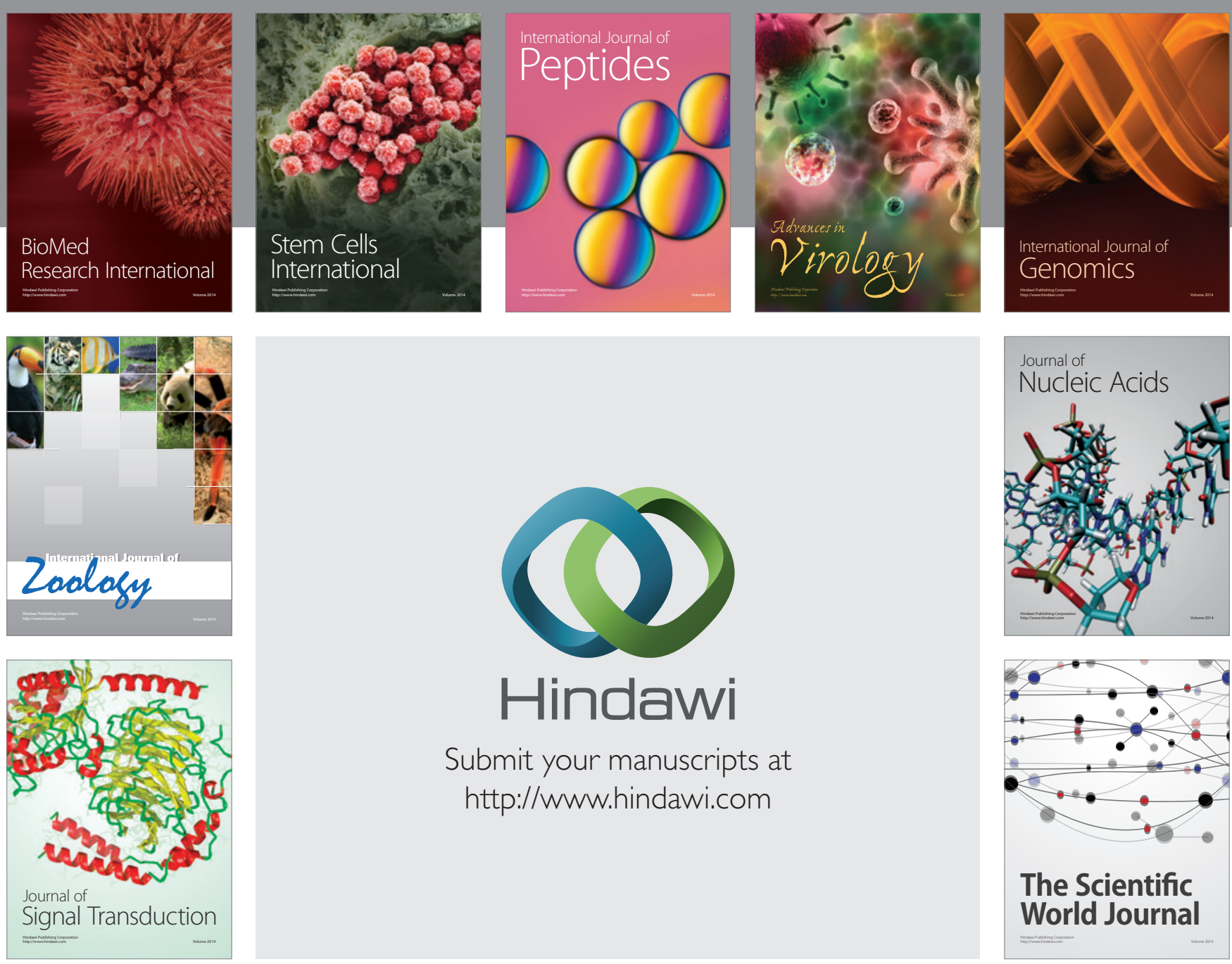

Submit your manuscripts at

http://www.hindawi.com
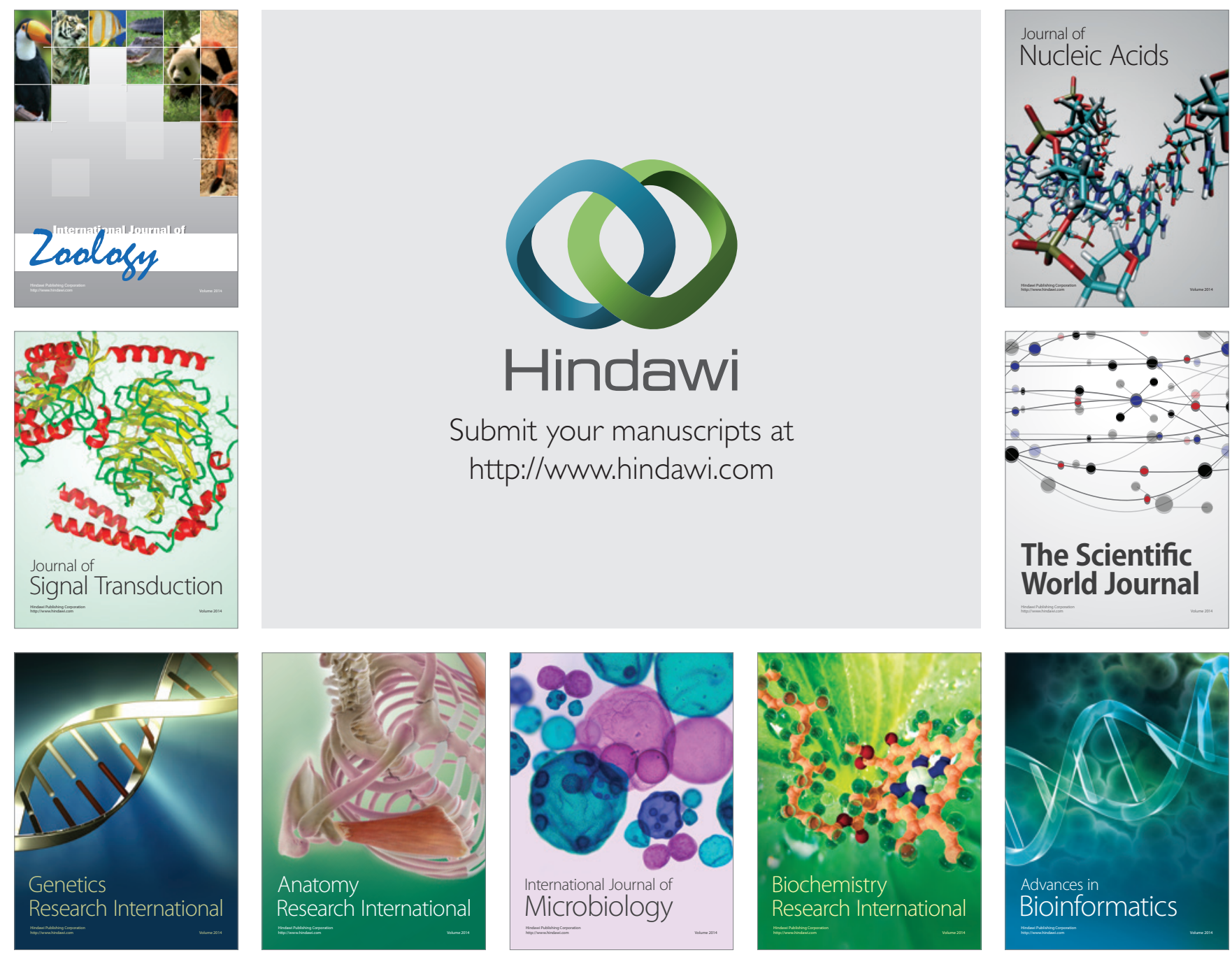

The Scientific World Journal
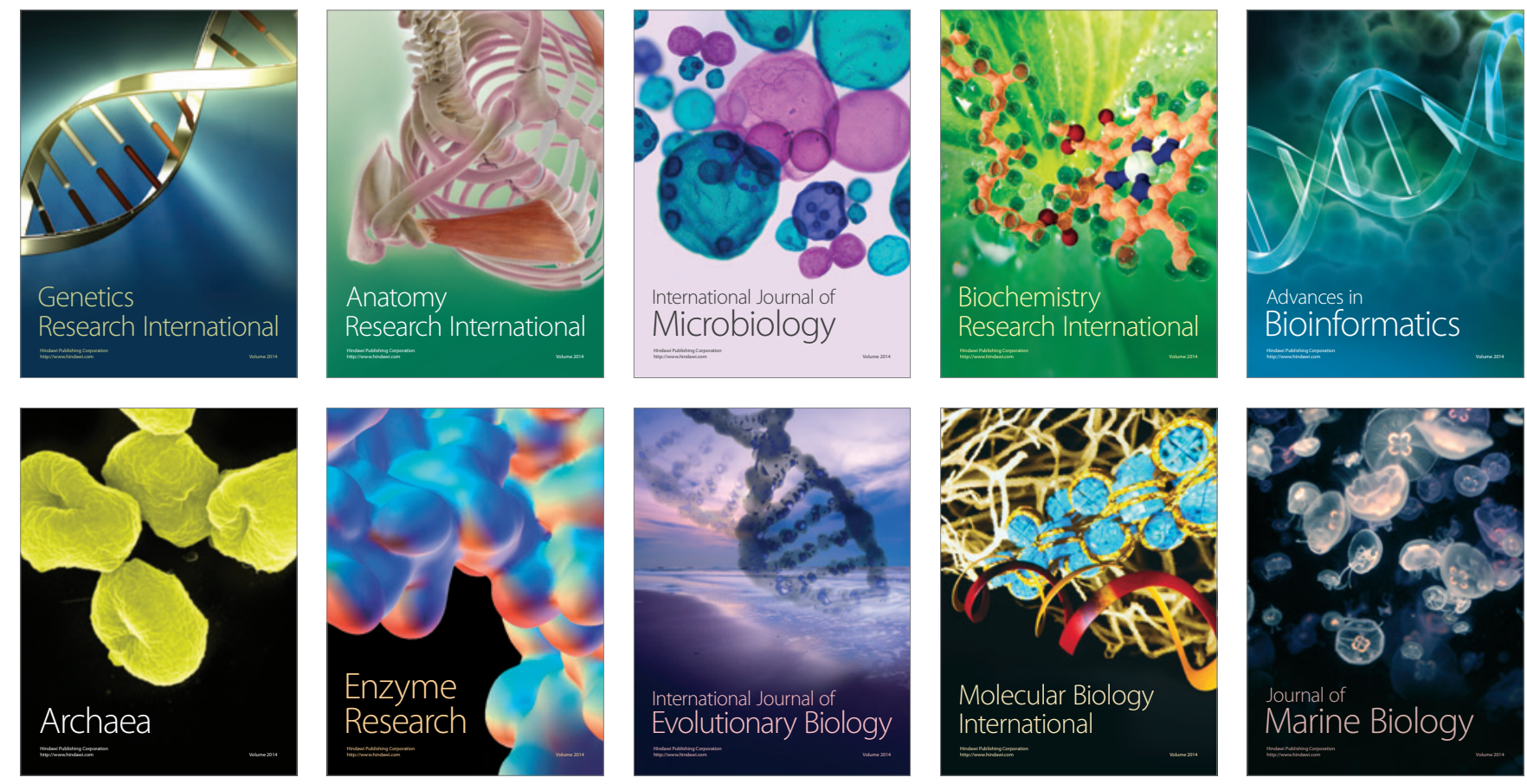